\title{
The Dynamics of Limits to Arbitrage: An Empirical Investigation
}

\author{
Andrea Buraschi * $\quad$ Emrah Sener ${ }^{\dagger} \quad$ Murat Menguturk ${ }^{\ddagger}$ \\ January 15, 2011
}

\begin{abstract}
We study empirically the dynamic properties of the limits to arbitrage in the sovereign bond market around a period of market distress. The recent credit crisis offers a unique opportunity to investigate the economic causes of limits to arbitrage. We consider markets that were liquid pre-crisis, and use pairs of sovereign bonds that have been issued in two foreign currencies, i.e. usd and euro. A simple theoretical arbitrage relationship links their credit spreads. While these bounds are within bid/ask spreads during the normal time, they are severely violated during periods of financial stress. As an example, in December 2008 Brazil euro-denominated credit spreads on 10-year Eurobonds were nearly $35 \%$ higher than the same credit risk denominated in usd. We construct an empirical proxy of limits to arbitrage and run a comprehensive investigation about its economic and behavioral drivers. We find that limits to arbitrage are time-varying and state-dependent. Given that the 2008 Crisis went through two distinct phases (i.e. liquidity crunch and credit crisis), our findings suggest that while sentiment risk and subjective uncertainty affect the first phase, it is funding risk that plays a central role. After the collapse of Lehman Brothers, however, perception of tail event risk and fundamental-related macro risks drive the dynamics of the limits to arbitrage.
\end{abstract}

Keywords: Emerging Market Eurobonds, Credit Risk Premiums, Limits to Arbitrage

$1^{\text {st }}$ Version: November $18^{\text {th }}, 2010$

$2^{\text {nd }}$ Version: January $14^{\text {th }}, 2011$

*a.buraschi@imperial.ac.uk, Andrea Buraschi is Professor of Finance at Imperial College Business School, Imperial College London

†emrah.sener@ozyegin.edu.tr, Emrah Sener is Director of Center for Computational Finance, Ozyegin University

${ }^{\ddagger}$ m.menguturk@imperial.ac.uk, Murat Menguturk is PhD candidate at Imperial College Business School, Imperial College London 


\section{Introduction}

This paper is an empirical study of the properties of violations of the law of one price in the sovereign bond market around a period of market distress. We investigate the extent to which limits to arbitrage are statedependent and how they have been affected before, during and after credit/liquidity crises.

The majority of sovereigns and multinational corporates issue debt across more than one foreign currency. Brazil, for instance, issues a considerable amount of usd- and euro-denominated bonds having similar, if not identical time-to-maturities. One may suppose that the risk premiums (of a single issuer) across currencies should only be a function of Brazil's unit-free creditworthiness and the corresponding risk free rates. In December 2008, however, Brazil's euro-denominated credit spread on 10-year Eurobonds, was nearly 35\% higher than the same credit risk denominated in usd; this difference was only $4 \%$ in November 2005 . Was the law of one price temporarily impaired in the markets, and were arbitrageurs able to profit from such shocks via buying the cheaper Eurobond and selling the more expensive one? If arbitrageurs were indeed able to take such positions in sufficient size, the temporary anomaly in markets would be soon expected to vanish, as bond prices would be driven back to fundamentals. Nonetheless, the differentials in the same credit risk (across two currencies) continued to widen in disproportional magnitudes for two years, begging therefore the following important questions: Why did the rational arbitrageur, though given the market opportunity, refrained from taking this opportunity; and what type of market limitations and costs actually caused the corresponding risk premiums to widen so drastically and continuously for a long period of time?

The law of one price (LOP) requires that two assets generating equal cash-flows have equal values. Otherwise, there exists an arbitrage opportunity. Arbitrageurs play an essential role in eliminating mispricings, providing liquidity to economy, thus allowing asset prices to reflect market fundamentals. While significant deviations from the law of one price are certainly not common, the recent credit crisis offers a unique laboratory to study such an important phenomena. While one may not be surprised to see scattered evidence of violations of the LOP in small and illiquid markets, it is of greater intellectual interest to study the properties of such violations in large and liquid markets. To address these questions, we analyze the three most important emerging sovereign bond markets (by notional amount outstanding) that have bonds issued in both usd and euro (i.e. Turkey, Brazil and Mexico). We then proceed in three steps. First, we calculate a proxy of deviation from the LOP based on the differential between the two credit spreads on bonds from the same issuer but denominated in different currencies. Exchange rate risk is taken into account to form a variable that we call the limit to arbitrage proxy (LtA). If the LOP holds, LtA should be equal to zero. Indeed, we find that during the normal market conditions (i.e. pre-crisis) the LtA was close to zero, within bid/ask bounds. The depth of the market guaranteed an easy implementation of an arbitrage position if LtA were to diverge too much away from zero. However, this did not hold true for an extended period of time across all three bond markets. Second, we investigate whether LtA is state-dependent. We divide the entire data into three main sub-samples (i.e. pre-crisis, crisis and after-crisis) and investigate whether (and when) LtA is nonzero, and what potential market factors drive it. We consider eight alternative potential explanations; accordingly we organize the right-hand-side variables in eight different subsets: funding limitations, frictions, macro-activity risk, sentiment risks, local equity/credit risk, perceived tail event risk, subjective uncertainty and long-run risk factors. We study the relative importance of each of these factors, for each of the three markets, during each different phase of the 2008 Crisis. The third important goal of the paper is to find whether credit risk models can make the assumption of currency independence and employ usd as the de facto currency to price also euro-denominated products of the same issuer. This is an important question since there is a tendency in most financial institutions to employ usd as de facto currency to price all other foreign currency-denominated credit 
products. The implicit assumption is that usd spread is a perfect substitute to discount risks denominated in the other currencies, given that risk premia (of a single issuer) across two currencies are identical. While under certain theoretical conditions this assumption is in fact correct, the question of whether it holds up empirically needs to be examined.

The estimation of the term structures of Eurobond credit risk premiums is based on the Nelson SiegelSvensson model. Term structure of Eurobonds is decomposed into risk-free and credit spread curves, and the parameters are estimated jointly from a combined set of data (see also Houweling et al. (2001)). The data set consists of weekly observations of bid and ask yields for a total of 30 euro-denominated Eurobonds, and a total of 56 usd-denominated Eurobonds issued by Turkey, Brazil and Mexico. We specifically choose these three markets since they are the top three emerging countries in terms of sovereign bond issuance in dual (foreign) currencies during the given period July 2005 - April 2010. The data includes the sub-prime crisis and the collapse of Lehman Brothers in September 2008. Accordingly, we break down the entire period into pre-crisis, crisis and after-crisis periods. Such examination helps to evaluate the structural changes in the determinants of LtA. The pre-crisis period starts on July 1st, 2005 and ends on August 8th, 2007, whereas the crisis period starts on August 9th, 2007 and ends with March 31st, 2009. The crisis period is divided further into two additional subsamples: the liquidity crisis (9 August 2007 - 29 August 2008) and the credit crisis (1 September 2008 - 31 March 2009). This additional subdivision is to investigate effects of subprime crises and the collapse of Lehman Brothers on LTA. The after-crisis period, on the other hand, begins with 1 April 2009 and ends with 30 April 2010.

We find a number of empirical results. First, LtA is state-dependent. Before the crisis, LtA is not significantly different from zero. The sovereign bond market is liquid and any deviation from the LOP is quickly arbitraged away. During the crisis, however, the widening of the LtA proxy shows significant violations of LOP. Four factors from the potential eight are statistically significant in explaining the dynamics of LtA: sentiment risk, funding risk, subjective uncertainty, and long-run economic growth risk. Thus, we find that LtA is explained by both behavioral factors (sentiment) and factors related to fundamentals. Empirically, this finding validates the theoretical arguments of Gromb and Vayanos (2010). More than $70 \%$ of the total variation in LtA proxy can be explained only by US market components during the credit crisis, suggesting how sensitive the EM Eurobond cash flows are to the spillover effects from large funding capital markets. This finding also implies that the risk exposure of arbitrageurs should be assessed at a global level, and not necessarily at a sovereign-specific level (see also Longstaff (2008) et al.). In the post-crisis period, two findings stand out: LtA levels become progressively much smaller and more quickly mean-reverting to zero; while LtA volatility remains at levels higher than in the pre-crisis period.

Our second finding is related to the price discovery in the corresponding risk premiums, which shed light to the natural habitat of traders. First, it must be noted that Brazil and Mexico pay higher and more volatile risk premia in euro compared to usd, while for Turkey the opposite holds true. Furthermore, the usd-denominated bonds in Brazil and Mexico also contribute more to the price discovery process than their euro-denominated equivalents. On the other hand, Turkish euro-denominated bonds tend to lead the price variations of usddenominated bonds. Bonds that have better price discovery contribution are also less volatile. This may be suggestive of the fact that the natural habitat of arbitrageurs may be different depending on the currency denomination used to fund operations across markets, which appears to be the usd for Mexico and Brazil, and euro for Turkey.

Finally, our third finding is related to whether usd spread can in fact be used as de facto input for the pricing of the same credit risk, denominated in different currencies. While this appears to be a popular 
approach, we find that investors require different premia on usd- and euro-denominated bonds of the same issuer. Thus, the assumption of currency-independence may lead to seriously mispriced credit products in the market. It is empirically incorrect to treat usd spread as de facto reference currency in the valuation of foreign-denominated credit products of the same issuer, and hence, the credit pricing models should be built taking into account the funding risks which are specific to each corresponding currency.

The paper is organized as follows: Section 2 outlines the results in the literature that are related to our work. Section 3 gives the theoretical framework for our empirical investigation of the dynamics of limits to arbitrage, including the definition of currency dependence and the derivation of cross-asset arbitrage in an intertemporal setting. Section 4 details the data selection and discusses the possible determinants that explain the dynamics of limits to arbitrage. Section 5 gives the methodology use to obtain the credit spread curves via the Joint Estimation Method, and discusses the price discovery and the fixed-effects panel regressions concerning the LtA. Section 6 discusses the empirical results. Section 7 concludes.

\section{Literature Review}

This paper is related to three streams of the asset pricing literature. A vast body of work investigates market anomalies that appear to be unrelated to economic fundamentals. A part of this stream studies the predictability of asset returns and presents evidence that stock returns are predictable either based on past earnings (the post-earnings announcement drift puzzle by Bernard and Thomas, 1989), and short-run momentum effects (Jegadeesh and Titman, 1993). A second part of this literature investigates the behavior of relative asset prices and violations of the LOP, including the Siamese-Twin stocks puzzle by Rosenthal and Young (1990), the Palm-3Com spin-off puzzle by Lamont and Thaler (2003) and put-call parity deviations by Ofek et al. (2004). ${ }^{1}$ While our study is more directly related to the latter, an important point of differentiation is both the structure of our data and type of questions we ask. The empirical analysis is based on data from a very large market, and potential violations are systematic and persistent, as opposed to being related to a set of isolated events. Our LtA proxy is obtained in a fairly simple framework, in a context in which security pairs have nearly matching cash flows, and can be analyzed empirically in a market with high liquidity and data accessibility. Moreover, our empirical framework allows us to address a different question than the previous related literature, namely whether limits to arbitrage are state-dependent. We try to quantify the relative importance of different sources of risks to explain limits to arbitrage and their interaction during systemic events.

A second stream of the literature studies the implications of financial constraints on the equilibrium asset prices. This literature has taken two directions. The first deals directly with different type of financial constraints, such as short selling (Tuckman and Vila, 1992), equity capital borrowing (Shleifer and Vishny, 1997) and the role of collateral value (Bernanke and Gertler, 1989, Fostel and Geanakoplos, 2008), limited risk capital (Gabaix et al., 2007, Garleanu and Pedersen, 2007), market liquidity risk (Acharya and Pedersen, 2005, Mitchell et al., 2007), leverage constraints (Gromb and Vayanos, 2002) and banking frictions (Allen and Gale 2004). A second part of this literature studies the implications of these frictions in terms of welfare and public policy. Gromb and Vayanos (2010) highlight the role of specialized institutions in the optimal allocation of capital and their impact on socially optimal decisions, and whether this has relevant public policy implications. Krishnamurthy (2010) argues that the financial crises, including the subprime and Lehman collapse, provide a compelling example that government intervention can be important for the smooth functioning of financial

\footnotetext{
${ }^{1}$ Refer to Gromb and Vayanos (2010) for an excellent treatment of the main literature on market anomalies.
} 
markets. One can view these government interventions as a way to reduce limits of arbitrage in financial markets, thus closing the gap between market prices and fundamental values. Since the financial sector can have a systematic role for the allocation of resources in the real economy, financial distress may lead to welfare costs. Geanakoplos and Polemarchakis (1986) show that in the presence of market frictions, market incompleteness create the possibility of Pareto improvements triggered by public intervention. In that sense, the research on limits to arbitrage is linked to the debates on the optimal design of public policies during financial crises.

Our paper is also related to a third stream of the literature that deals with credit risks and derivatives pricing. It is common market practice among investment banks, data suppliers (i.e. Reuters and Bloomberg) and rating agency companies (i.e. Moody's and Standard Poors) to employ usd as an input to price the credit risk of products that make reference to the same issuer, even across different currency denominations (Merrill Lynch, 2000). The major assumption is that the FX market is liquid and deep enough to make the usd a perfect substitute for other currencies. Studies of corporate spreads have suggested that credit spreads can be decomposed into three components: default, tax and risk premia (see Elton et al., 2001); Collin-Dufresne et al. (2001) find evidence of the existence of an unexplained systemic factor affecting credit spreads; other studies include the default risk component verification by Longstaff et al. (2005) and the heterogeneous beliefs by Buraschi et al. (2009). ${ }^{2}$ Little attention has so far been given to the risk premiums in a multi currency setting. Domowitz et al. (1998) discuss the response of country/currency risk premiums to market volatility; Kercheval et al. (2003) argue that risk premiums of a single issuer, across two currencies, should be of the same sign and magnitudes; Ehlers and Schönbucher (2004) highlight the impact of the sudden devaluations (jumps) on the differences between the risk premiums across two currencies; Jankowitsch and Pichler (2005) suggest that the cross-sectional risk premiums must be identical for a single issuer as long as the default variables and exchange rates are uncorrelated; and finally, Landschoot (2008) shows how corporate credit spreads in two different currencies (i.e usd and euro) of two different issuers (i.e US and Euro Zone) respond to various yield and market factors.

\section{Theoretical Framework}

In order to explore the concept of limits to arbitrage in the sovereign Eurobond market, we first briefly outline the credit spreads properties in a frictionless economy when a country issues bonds across two different currencies: usd and euro. This leads to the definition of currency dependence of credit spreads, and the discussion of the underlying assumptions that make it equal to zero. Then, we use these results to define a variable called $L t A$ (Limits to Arbitrage) that is defined as the deviation from the theoretical no-arbitrage relation that should prevail in a frictionless economy. In the empirical part, we will use this variable to study the relative importance of difference sources of frictions that can impair this link.

\footnotetext{
${ }^{2}$ Although Elton et al. (2001) and Collin-Dufresne et al. (2001) focus on a single currency, they provide powerful insights into how cross-currency credit risk premiums should behave in the market. Their results support that the credit risk premium of a single issuer cannot be explained by only a unit-free default risk. This implies that credit risk premiums, empirically shown to be related to unit-bearing determinants, may indeed differ across currencies. Refer to Fons (1987) to see whether the actual default rates of low-rated corporate bonds are representative of the risk premiums required by the investors. To study papers that divide corporate credit spreads into various components, refer to, for example, Duffee (1999), Driessen (2005), Ericsson and Renault (2006), Chen et al. (2007) and Feldhütter and Lando (2008).
} 


\subsection{Eurobonds in Emerging Markets}

A Eurobond is a bond issued in a currency other than the currency of the sovereign (or corporate) that issues it. Given local currency and potential governance risk, the majority of emerging countries issue Eurobonds denominated in usd and/or euro, with maturities ranging from 1-30 years. ${ }^{3}$ Compared to the euro market, the usd market is more liquid, and is larger in terms of outstanding volume. This reflects the historical differences of the two regions: Europe has been mainly driven by a bank-based system, while the US has relied on a market-based structure. Although the issuance of euro-debt declined considerably following the 2001 Argentina crisis, a new trend of euro funding occurred in emerging markets starting from 2004, and after 2005 both euro and usd markets became broadly similar in terms of activity and issuance. ${ }^{4}$

\subsection{Currency Dependence in Emerging Markets}

Eurobonds bear both a credit and a liquidity risk premium over their risk-free equivalents. If we define the risk-free rate in currency $c$ (i.e. usd or euro) as $r_{c}$, and the Eurobond rate issued in currency $c$ as $R_{c}$, then the credit risk premium $S_{c}$ is the yield spread between $R_{c}$ and $r_{c}{ }^{5}$ This is the risk that the sovereign might default on its obligations by either postponing or refusing to repay its foreign debt. Therefore, if the time to maturity is denoted as $T$, we can define the credit risk premium at time $t$ as

$$
S_{c}(t, T)=R_{c}(t, T)-r_{c}(t, T)
$$

Risk-free rates, default probabilities and recovery rates are the three main factors driving the dynamics of credit risk premia. A vast literature has investigated the issue of credit risk pricing in the context of corporate debt. Less evidence is available with regards to the international debt market. As Duffie et al. (2003) point out, the nature of sovereign credit risk is considerably different than corporate debt. First, sovereign default is both a political and financial decision, and is not subject to the same well-defined corporate bankruptcy code. As Bulow and Rogoff (1989) state, the collateral is not a relevant element for sovereign bonds, and the contract is often subject to renegotiations before default, which further complicates the matter. ${ }^{6}$ Davydenko and Franks (2008) argues that bonds issued in local and foreign currencies are subject to different jurisdictions, which have varying impacts on the corresponding recovery rates. For this reason, we are careful not to consider credit spreads between local and foreign denominated bonds. Instead, we consider Eurobonds issued by the same sovereign across two foreign currencies (i.e. usd and euro): recovery rates are therefore subject to the same foreign jurisdictions and can assumed to be identical, ${ }^{7}$ thus eliminating any potential influence due to the recovery rates.

\footnotetext{
${ }^{3}$ Boehmer and Megginson (1990) state that although lending to developing markets virtually stopped when Mexico declared moratorium in August 1982, the secondary market trading volume began to grow steadily after 1986 mostly due to the advantages of debt-conversion programs.

${ }^{4}$ At year-end 2005, total Turkish external public debt in US dollars, including both usd and euro Eurobonds, was 39.9 billion usd at the then-prevailing exchange rate. Of that amount, $76 \%$ consisted of usd Eurobonds, with another $24 \%$ accounted for by euro Eurobonds. At the same period, total Brazilian external public debt in US dollars, including both usd and euro Eurobonds, was 22.9 billion usd at the then-prevailing exchange rate. Of that amount, $80 \%$ consisted of usd Eurobonds, with another $20 \%$ accounted for by euro Eurobonds. At the same period, total Mexican external public debt in US dollars, including both usd and euro Eurobonds, was 20.1 billion usd at the thenprevailing exchange rate. Of that amount, $89 \%$ consisted of usd Eurobonds, with another $11 \%$ accounted for by euro Eurobonds. These statistics reveal that Turkey has the highest level of external sovereign borrowing, and that each country issues more usd-denominated bonds than euro-denominated bonds.

${ }^{5}$ Hull et al. (2004) and Blanco et al. (2005) suggest that in a no-arbitrage environment, this rate differential should approximately be equal to the credit default swap rates.

${ }^{6}$ See Eaton et al. (1986) for the theoretical differences between corporate and sovereign debt. For debt servicing capacities of developing markets, see Feder et al. (1981). For surveys of the literature on the analysis of country default risk, see Saini and Bates (1984).

${ }^{7}$ Tax treatment for the usd- and euro-denominated Eurobonds for EM is the same.
} 
In all known instances of foreign default, countries have always defaulted on their foreign denominated debt independently of their currency of denomination. For this reason, it is common to assume that default probability is unit-free and unique to the issuer, suggesting that the risk premia across currencies are identical. This eliminates the influence of default probability in the differential of expected cash flows between bonds in different currency denominations. Let us define Currency Dependence ( $C D$ thereafter) of country $j$ at time $t$ as follows:

$$
C D^{j}(t, T)=S_{u s d}^{j}(t, T)-S_{\text {euro }}^{j}(t, T)
$$

Therefore, the Currency Dependence is the differential of the premia that the sovereign pays for the two Eurobonds denominated in the two foreign currencies. In general, in a frictionless economy it may be argued that the choice of a numeraire should not affect the properties of asset prices and returns (i.e. level of expected returns, volatility, autocorrelations). Kercheval et al. (2003) argue that if the company issues bonds across currencies, one can suppose that the credit risk is a function of that company's creditworthiness only, and not of the currency the bond is issued in. They derive a covered interest arbitrage condition, where changes in credit risk premia (of a single issuer) across two currencies are perfectly correlated. Similarly, Jankowitsch and Pichler (2005) prove that currency dependence must be equal to zero under the assumption of zero correlation between credit spreads and exchange rates, i.e. $C D^{j}(t, T)=0$. One could therefore define as a proxy of the extent of arbitrage violation a variable $L t A^{j}(t, T)$, with $L t A^{j}(t, T)=C D^{j}(t, T)$. A joint hypothesis of zero correlation and no friction is equivalent to test whether $H_{0}: L t A^{j}(t, T)=0$. If correlation is non-zero, however, the currency dependence may be non-zero even in absence of frictions. Thus, in what follows, we discuss how currency dependence is affected by the correlation between credit spreads and exchange rates.

\section{Cross-Asset Arbitrage in Intertemporal Setting}

Consider a frictionless economy in which a single sovereign issues bonds in two foreign currencies: usd and euro. The risk premiums of these bonds are denoted as $S_{\text {usd }}(t)$ and $S_{\text {euro }}(t)$ for usd and euro, respectively. Consider a strategy in which an arbitrageur at time $t$ can long the euro-denominated credit risk $S_{\text {euro }}(t)$ via buying euro-denominated Eurobond of country $j$ for an amount equal to $M^{e}$, and short an equivalent amount of usd-denominated credit risk $S_{u s d}(t)$ via selling usd denominated Eurobond of the same country for an amount equal to $M^{e} / X_{t}$, where $X_{t}$ denotes the USDEUR exchange rate (euro per unit of usd) at time $t$. At time $t+\delta t$, the credit risk premiums would be $S_{\text {euro }}(t+\delta t)$ and $S_{u s d}(t+\delta t)$, respectively. Similar to the theoretical setting of Gromb and Vayanos (2010), this arbitrage strategy has two interpretations, both representing real arbitrage situations. In the first interpretation (i.e. cross-asset arbitrage), there are two different assets, and arbitrageurs use usd-denominated bonds to hedge their positions in euro-denominated cash flows. In the second interpretation (i.e. intertemporal arbitrage), there is one asset, and arbitrageurs take advantage of the price anomalies of a single asset at different points in time. ${ }^{8}$ The two interpretations yield the same basic insight: the equilibrium prices of Eurobonds are closely related to the level of risk-aversion of arbitrageurs against exogenous shocks, which pull prices away from fundamentals. For this reason, in the empirical analysis we split our time period into three different sub-sets: pre-crisis, crisis, and after crisis periods, presumably affected by different levels of risk aversions.

\footnotetext{
${ }^{8}$ Grossman and Miller (1988) emphasize that it takes time for enough risk-bearing capacity to arrive in the market and fully eliminate the effect of the mispricing.
} 
The arbitrageur's profit (loss) of the strategy denominated in euro, $\Delta \Pi_{t}$ is:

$$
\Delta \Pi_{t}=\left(S_{t+\delta t}^{e}-S_{t}^{e}\right) M_{t}^{e}-\left(S_{t+\delta t}^{\$}-S_{t}^{\$}\right) \frac{M^{e}}{X_{t}} X_{t+\delta t}
$$

If we divide $E\left[\Delta \Pi_{t}\right]$ by $C_{t}^{\$}$ and then again by $\frac{M^{e}}{X_{t}}$, we obtain:

$$
E\left[\Delta \Pi_{t}\right]\left(\frac{X_{t}}{M^{e} C_{t}^{\$}}\right)=E\left[\left(S_{t+\delta t}^{e}-S_{t}^{e}\right) X_{t}-\left(S_{t+\delta t}^{\$}-S_{t}^{\$}\right) X_{t+\delta t}\right]
$$

Or, equivalently

$$
E\left[\Delta \Pi_{t}\right]\left(\frac{X_{t}}{M^{e} C_{t}^{\$}}\right)=E\left[\left(S_{t+\delta t}^{e}-S_{t}^{e}\right) X_{t}\right]-E\left[\left(S_{t+\delta t}^{\$}-S_{t}^{\$}\right)\right] E\left[X_{t+\delta t}\right]-\operatorname{Cov}\left(S_{t+\delta t}^{\$}-S_{t}^{\$}, X_{t+\delta t}\right)
$$

The expected profits of the arbitrageur is directly affected by the covariance between the credit risk premium and the USDEUR exchange rate. According to the uncovered interest rate parity, $\frac{\mathbb{E}\left[X_{t+\delta t}\right]}{X_{t}}=\frac{1+r^{E}}{1+r^{\Phi}}$, with $r$ being the risk free interest rates $t$ and $t+\delta t$. Dividing by $X_{t}$, we obtain:

$$
\frac{E\left[\Delta \Pi_{t}\right]}{M^{e} C_{t}^{\Phi}}=E\left[\left(S_{t+\delta t}^{e}-S_{t}^{e}\right)\right]-E\left[\left(S_{t+\delta t}^{\Phi}-S_{t}^{\$}\right)\right] \frac{1+r^{E}}{1+r^{\Phi}}-\operatorname{Cov}\left(S_{t+\delta t}^{\Phi}-S_{t}^{\$}, \frac{X_{t+\delta t}}{X_{t}}\right)
$$

However, if the covariance is not zero, the arbitrageur would earn (normal) expected profits given by the expression on the right hand side of Eq. (7). We call $L t A$ the deviation of the profits from the parity defined as follows:

$$
L t A=E\left[\left(S_{t+\delta t}^{e}-S_{t}^{e}\right)\right]-E\left[\left(S_{t+\delta t}^{\Phi}-S_{t}^{\$}\right)\right] \frac{1+r^{E}}{1+r^{\Phi}}-\operatorname{Cov}\left(S_{t+\delta t}^{\Phi}-S_{t}^{\Phi}, \frac{X_{t+\delta t}}{X_{t}}\right)
$$

For instance, if the covariance term were zero then if $\mathbb{E}\left[S_{t+\delta t}^{e}-S_{t}^{e}\right]=\left[\frac{1+r^{E}}{1+r^{\Phi}}\right] \mathbb{E}\left[S_{t+\delta t}^{\$}-S_{t}^{\$}\right]$ arbitrageurs would earn zero expected profits. Which also implies that credit spreads should equate across currency denomination up to a scale factor equal to the ratio of the risk free interest rates. Interestingly, before the 2008 crisis, this is indeed what we find in the data.

In the rest of the paper, we focus on the dynamics of $L t A$ for three sovereign markets before, during, and after the credit crisis. The existence of a value for $L t A$ significantly different than zero can be interpreted in two different ways: (a) Markets are inherently inefficient, and hence, there exist inherent arbitrage opportunities (b) Markets are inefficient because arbitrageurs are unwilling (or incapable) to take arbitrage positions. We first estimate $L t A$ over different periods to see how frequently $L t A$ is within the bid/ask spread bounds. Then, under a magnifying glass we study the periods in which we observe violations that imply the existence of an unused arbitrage opportunity, and investigate what specific factors drive these violations. This is important since it can help our understanding of market behavior, and shed some light on the debate between neoclassical economics, behavioral finance and the limits to arbitrage literature.

\section{Data Description}

The weekly data set covers the period July 2005 - April 2010, and is divided into three main sub-samples (and two further sub-samples for crisis period). Bernanke (2009) discusses that during the 2007-2009 financial crisis, both liquidity and credit risks have been quite important, but at different stages and to different degrees. As an explanation to the Federal Reserve's response to the crisis, he also argues that during the first stage of the 
crisis, the Federal Reserve provided liquidity to solvent institutions with minimal credit risk. However, during the second stage of the crisis, the Federal Reserve accepted some credit risk by providing capital to some impaired borrowers and markets in order to directly address counterparty credit risk. Similarly, according to Longstaff (2010), the recent financial market turmoil can be divided into two major subperiods, namely a liquidity and a credit crisis period. We follow Taylor and Williams (2009) and Longstaff (2010) and assume that the beginning of the liquidity crisis coincides with the BNP Paribas's suspension of redemptions of 2 billion USD asset-backed funds; whereas we assume credit crisis to begin one week before the Federal Housing Finance Agency's decision of placing Fannie Mae and Freddie Mac in government conservatorship in September $7^{\text {th }}$, and two weeks before the Lehman Brothers collapse in September $15^{t h}$. To summarize:

1. Pre-Crisis Period: 1 July 2005 - 8 August 2007

2. Crisis Period: 9 August 2007 - 31 March 2009

(a) Liquidity Crisis: 9 August 2007 - 29 August 2008

(b) Credit Crisis: 1 September 2008 - 31 March 2009

3. After-Crisis Period: 1 April 2009 - 30 April 2010

\section{Eurobond Yields}

The data set for Eurobonds is based on two different sources: Bloomberg and Reuters 3000 EXtra. Weekly bid-ask yields and prices for euro- and usd-denominated bonds for four maturity buckets (1-3 years, 3-6 years, 6-9 years and 9-15 years) are retrieved from Bloomberg for the three largest EM sovereign issuers who issued in dual currencies: Turkey, Brazil and Mexico. ${ }^{9}$ It must be noted that these countries are the only ones that issued sufficient amount of bonds across both currencies during the given time interval. Characteristics of bonds are collected from Reuters 3000 EXtra: all bonds have fixed coupon rates and are neither callable, puttable, structured nor convertible. Brady Bonds are excluded. ${ }^{10}$ To minimize the problem of bond illiquidity, prices are collected as Bloomberg Generic (BGN), which are generated by removing extreme values, and taking weighted averages of quotes (firm and indicative) submitted by a minimum of five brokers. Firm quotes are often assigned a higher weight than indicative quotes. Bloomberg Fair Value (BFV) prices, which are obtained via optimization algorithms, are not used in our data set. The number of bonds denominated in usd are greater than that in euro for all maturities, and the number of long-term bonds are greater than that of short-term bonds. As of July 2005, the number of usd- and euro-denominated bonds are displayed in Table 1.

\section{[Insert Table 1 here]}

For the estimation of EM risk premiums, we need to identify the proxy for risk-free curves. Grinblatt (2001) suggest using swap rates as default-free benchmarks; similarly, Houweling and Vorst (2005) argues that swap curves are preferable than the government curve as a corresponding proxy. Feldhütter and Lando (2008) make a similar argument. In our paper, we use both the swap rates and the interbank rates as the benchmark

\footnotetext{
${ }^{9}$ The given Emerging Markets are also members of Morgan Stanley Capital International (MSCI) Emerging Markets Equity Index. As of 2008, MSCI consists of China, Indonesia, Philippines, Korea, Malaysia, Taiwan, Thailand, Pakistan, India, Russia, Israel, Jordan, Egypt, Turkey, Morocco, South Africa, Poland, Czech Republic, Hungary, Peru, Mexico, Chile, Colombia, Brazil and Argentina.

${ }^{10}$ Claessens and Pennacchi (1996) argue that the prices of Brady bonds, having third-party guarantees, do not accurately reflect a country's fundamental creditworthiness, and hence require additional adjustments to capture the effects of the given credit-enhancements.
} 
risk-free curve for different parts of the term structure. For the estimation of US risk-free curves, we use 6-12 month London Interbank Offer Rates (LIBOR) at the short end, and 1-30 year maturity US swap rates at the long end. Similarly, for euro risk-free curves, we use 6-12 month Euro Interbank Offer Rates (EURIBOR) for short-end, and 1-30 year maturity euro swap rates for the long-end of the term structure. The estimation methodology for the risk premiums across currencies is explained in Section 5.

\section{[Insert Table 2 here]}

Table 2 highlights the statistics regarding the mean and volatility of the corresponding risk premiums. In all three sample periods, Turkey on average pays the highest risk premium in usd, followed by Brazil and Mexico. This ranking is consistent with Moody's credit ratings during the majority of the period when Turkey had the lowest bond quality, and Mexico had the highest. ${ }^{11}$ Furthermore, Turkey is higher and more volatile in its usd risk premiums than it is in the euro risk premiums. On the contrary, Brazil and Mexico, on average, pay higher and more volatile risk premiums in euro. ${ }^{12}$ In short, however, it is easily observed from Figure 1 that the usd and euro risk premia are not identical for the given three emerging countries during the given sample period. ${ }^{13}$

[Insert Figure 1 Here]

Moreover, the risk premiums of Turkey, Brazil and Mexico in both currencies tend to increase in bond maturities. On the other hand, the same relation does not always hold with respect to bond volatilities. Credit risk premiums are highest between 1 September 2008 and 31 March 2009, which is consistent with our labeling this period as the credit crisis period. Table 2 clearly reveals that the magnitude and volatility of risk premiums increases monotonically from pre-crisis to the credit crisis period. The magnitude of usd risk premiums during the pre-crisis ranges from 6 basis points for bonds maturing in 1-3 years, to 165 basis points for bonds maturing in 9-15 years. While this range increases to 13 basis points for 1-3 year bonds and to 210 basis points for 9-15 year bonds during the liquidity crisis, the jump is even more substantial for bonds maturing in 1-3 years and 9-15 years, for which the increase is 150 and 515 basis points, respectively. During the credit crisis period, credit spreads traded at levels more than four times than their pre-crisis values, highlighting the far-reaching impact of the financial distress and illiquidity conditions to sovereign markets that were apparently not directly linked to the sub-prime crisis. The Lehman Brothers bankruptcy severely dislocated periphery bonds markets. It is interesting to observe that during the after-crisis period spreads levels of these sovereign bonds started to converge back not to their pre-crisis levels, but to their liquidity crisis levels, thus ranging from 60 basis points for 1-3 years bonds, to 270 basis points for 9-15 years bonds. A similar pattern can be found for their volatilities. Table 2 also reveals that the exact same pattern holds for euro risk premiums. While several studies focused on the dynamics of the level of credit spreads, our interest however is on the differential between usd and euro risk premiums. We observe that the absolute differentials during the pre-crisis period range between 1 to 33 basis points for 9-15 years bonds. During the liquidity crisis, this range rises up to 2 basis points for 6-9 years bonds and 45 basis points for 1-3 years bonds; during the credit crisis, the differential becomes 6 to 120 basis points for bonds maturing in 6-9 years and 1-3 years, respectively. We need to wait until the after-crisis period to see the differential to converge back to a range between 5 and 70 basis points for 3-6 years and 1-3 years bonds, respectively. These numbers are dramatic and

\footnotetext{
${ }^{11}$ In December 2009, however, Standard \& Poor's downgraded Mexico's credit rating from BBB+ to BBB.

${ }^{12}$ For further research, it would be interesting to investigate whether regional or economic proximity plays a role in the average and volatility of an issuer's credit risk premiums across currencies.

${ }^{13}$ Notice that Figure 1 summarizes the results for the 5 year maturities. Graphs for other maturity buckets are available from authors upon request.
} 
their persistence is very important for our understanding of no-arbitrage theory. Two implications emerge. First, investors require different compensations for usd- and euro-based credit risk, and the difference between the two widens considerably during periods of market distress. The market convention of using usd as a de facto reference currency in the valuation of foreign-denominated credit products is empirically incorrect and can lead to seriously mispriced credit products, especially if long-dated. This argument is also in line with the finding of Breger and Stovel (2005) that accurate that risk and pricing models need to include currency dependent factors, because spreads on all bonds from the same issuer are driven by different factors. Second, even large markets, such as sovereign bonds, can be subject to substantial limits to arbitrage. We can study their dynamics to understand their economic properties.

Limit to Arbitrage - LtA

Figures 2A-2C summarize the behavior of LtA, revealing three important elements: (a) During the precrisis period, LtA is not significantly different from zero: cross-asset arbitrage holds to a great extent and arbitrageurs can enforce equilibrium relationships; (b) during the crisis period, LtA values are large and highly volatile, suggesting that arbitrage relationship no longer holds empirically with the arbitrageurs, who are likely to be unable or unwilling to provide the liquidity necessary to enforce the LOP. ${ }^{14}$ It is also observed that violations are considerably higher during the credit crisis than they are during the liquidity crisis. This suggests that credit uncertainty has a first order effect on the dynamics of no-arbitrage relationships. (c) During the after-crisis period, LtA is gradually converging back to the levels prevailing in the liquidity crisis, not to those prevailing in the pre-crisis phase. This suggests that markets are in the process of stabilizing, with arbitrageurs relatively more capable of participating in financial markets and bringing asset prices back to fundamentals; and yet, the memory of initial market dislocation still affects asset prices. ${ }^{15}$ This points out an element of inertia in financial uncertainty. These findings hold consistently for all countries and all maturities.

[Insert Figures 2A-2C here]

Table 3 summarizes the summary statistics of the absolute values of LtA. Both the first and second moments of LtA tend to rise with the time-to-maturity of the underlying bond. In addition, the average and volatility increase monotonically from the pre-crisis to the credit crisis period. In the pre-crisis period, LtA fluctuates around zero by small magnitudes, ranging from 3 basis points for bonds maturing in 1-3 years, to 8 basis points for bonds maturing in 6-9 years. This indicates negligible constraints on arbitrageurs' activity. Later, during the liquidity crisis, the average LtA ranges 10 basis points for 1-3 year bonds, and 16 basis points for 3-6 year bonds. LtA levels increase even more sharply during the credit turmoil, ranging from 50 basis points for 1-3 year bonds to 90 basis points for 9-15 year bonds, thus increasing, on average, by more than ten times their pre-crisis levels. This is when the Eurobond markets enter their most distressed phase: either arbitrageurs were seriously constrained to access the capital necessary to absorb arbitrage opportunities, or behavioral biases were preventing arbitrageurs to close the gap. We also find that LtA in the after-crisis period bears close resemblance to the values during the liquidity crisis, implying once again that markets are gradually converging back to initial levels, but at a speed which is not consistent with standard theory and

\footnotetext{
${ }^{14} \mathrm{LtA}$ is almost sequentially positive and negative during this period. A high volatility (fluctuation) of this nature may bring the mean values close to zero. This gives indeed a valuable guidance on how to interpret the corresponding LtAs: if one is to simply evaluate the period by mean values, one would be seriously mistaken.

${ }^{15}$ We take FED's monetary policies as signs of economic stabilization in the after-crisis period.
} 
expectations. In the after-crisis period LtA range between 12 basis points for 1-3 years bonds and 22 basis points for 9-15 years bonds.

[Insert Table 3 here]

In order to appreciate LtA levels and its volatility, it is interesting to run a comparative analysis with the corresponding bond bid-ask yield spreads, which are also expected to widen during unstable periods, due to bond illiquidity. We find that although the bid-ask spreads indeed widen during the market distress, the increase in LtA far outstrips bid-ask spread bounds. We consider two main aspects: (a) the expected value of the differential between the absolute LtA value and the bid-ask yield spreads, the latter having been estimated as the difference between the bid and ask prices divided by the mid prices across both currencies, (b) the differential between the volatility of LtA and the volatility of bid-ask yields. Table 4 shows that in the pre-crisis phase, the first measure ranges between 0 basis points for 1-3 year bonds and 7 basis points for 9-15 years bonds. This suggests that any potential arbitrage opportunity is economically irrelevant during this period.

\section{[Insert Figures 3A-3C here]}

On the other hand, during the credit crisis, arbitrage opportunities, net of bid/ask cost, range between 48 and 80 basis points for 1-3 years and 9-15 years bonds, respectively. The differential is more than ten times the values in the pre-crisis period. Something other than transaction and liquidity costs must be at play to disallow arbitrageurs from providing liquidity to market and enforcing the LOP. ${ }^{16}$

[Insert Table 4 here]

\section{Determinants of LtA}

Arbitrage strategies in the EM Eurobond markets are carried out mainly by financial institutions like proprietary trading desks of investment banks and hedge funds. Any arbitrageur who wishes to implement a risky-arbitrage, as described in Section 3, needs to raise capital by either selling assets or borrowing funds. While investment banks can fund their operations with unsecured lines, hedge funds more commonly use secured funding agreements to implement their trade and source leverage. During normal market conditions, either funding strategies can be used without much difficulty. During times of financial distress, for instance around the Lehman collapse, this no longer holds: access to lending becomes limited through the secured funding channel, and collateral value takes center stage. Goldberg et al. (2010) points out that this is due to the shortages of lending in the market. Krishnamurthy (2010) argues that the reason is linked to funding restrictions (i.e. repo financing and haircuts), counterparty risk and risk-aversion, each reinforcing a contagious vicious cycle.

Since we are interested in studying the determinants of the dynamics of LtA, we consider the following potential sources of variation: Liquidity risk, Funding Risk, Macro-Activity Risk, Term Premia, Local and Global Equity Premia, Sentiment Risk, Perceived Tail Event Risk, and Subjective Uncertainty. Since Roll (1988), Goetzmann et al. (2005) and recently Longstaff et al. (2008) show that shocks to US financial markets

\footnotetext{
${ }^{16}$ See Figures 3A-3C for the absolute LtAs vs. US bid-ask spreads. The figures for the absolute LtAs vs. EU bid-ask spreads are available from authors upon request.
} 
have global effects, we decide to divide most determinants into two main categories: Global (US) Factors and Local (EM) Factors.

\section{Funding Factors}

- Liquidity and Frictions: Bond traders know that liquidity can have a profound impact on asset prices. Brunnermeier and Pedersen (2009) examines liquidity under two components: asset's market liquidity (the ease with which the asset is traded) and traders' funding liquidity (the ease with which traders can access funding). In their paper, they argue that traders do influence, and are influenced greatly by market liquidity conditions, and that the tightness of liquidity forces them to become reluctant in taking positions in high-margin securities, which in turn reduces market liquidity and increases volatility.

- Amihud and Mendelson (1986) argue that liquidity is a significant factor in the pricing of corporate bonds. In addition, Longstaff et al. (2005) point out the fact that a large portion of corporate spreads is due to default risk, but the time-varying nature of the non-default component is strongly related to bond-specific illiquidity. Similarly, Acharya and Pedersen (2005) find that corporate bonds carry a substantial liquidity risk premium. ${ }^{17}$ Hence, in our context, one could argue that idiosyncratic (or bond-specific) illiquidity may create a considerable amount of cross-sectional variation in the non-default component of risk premiums. We construct a weighted average bid-ask based measure of bond-specific liquidity as suggested in Amihud and Mendelson (1986). Assuming $b$ is a bond of country $j$ with time-to-maturity $m$ denominated in usd, the weighted average bid-ask spread, namely BIDASK, is calculated as follows:

$$
\operatorname{BIDASK}_{m t}=\sum_{b=1}^{N} w_{m t}^{b}\left(\frac{\text { Price }_{A s k}^{b}-\text { Price }_{\text {Bid }}^{b}}{\operatorname{Price}_{M i d}^{b}}\right)_{m t}
$$

where $w$ is the weight of bonds in the given maturity group, and Price Mid $_{\text {id }}$ isfined as the mean of bid and ask spreads of the bond in the given maturity group.

- A second measure of liquidity has been suggested by Buraschi and Menini (2002) and Fontaine and Garcia (2009). This measure captures global bond market liquidity from the repo specialness of U.S. Treasury on-the-run bonds. In the US, the repo market is a key funding market. Fontaine and Garcia (2009) measure the value of funding liquidity from the cross-section of on-the-run premia by adding a liquidity factor to an arbitrage-free term structure model. They argue that the premium of on-the-run U.S. Treasury bonds should share a common component with risk premia in other markets, such as LIBOR loans, swap contracts and corporate bonds. We use the Fontaine and Garcia (2009) proxy of liquidity, which we label FG-Liq, to capture the effect generated by a global (U.S.) liquidity factor. ${ }^{18}$

- Funding Risk: In theory, it is assumed that arbitrageurs have unfettered access to all capital markets. However funding costs depend on the level of capitalization and the risk of financial intermediaries. The empirical literature finds that the risk premiums, inherent in bond yields, tend to rise with tighter funding conditions. As discussed in Brunnermeier and Pedersen (2009), there are generally two types of

\footnotetext{
${ }^{17}$ Refer to Goldstein et al. (2007) for the effect of increasing transparency on corporate bond liquidity. Refer to Mahantia et al. (2008) for a discussion about latent liquidity and appropriate measures of liquidity risk in corporate bonds.

${ }^{18}$ Their funding liquidity value exhibits significant variations during normal and crisis periods. In particular, during the 1987 crash, the Peso devaluation of 1994, Long-Term Capital Management (LTCM) failure of 1998, and the recent 2007 liquidity crisis. We refer to their paper for in-depth discussion.
} 
traders involved in arbitrage opportunities: prop desks of investment banks and hedge funds. Although each of these traders chase similar arbitrage opportunities, they usually operate under different funding markets. While hedge funds borrow and lend against collateral on secured terms (secured arbitrage), investment bank prop desk participate in unsecured money market operations (unsecured arbitrage). Furthermore, as discussed in Kacperczyk and Schnabl (2010), commercial paper is an important source of financing (also known as money market financing) for the financial sector, playing a central role during financial crises. In this context, it is important to capture how difficult it is to roll-over risk-arbitrage positions to take advantage of market dislocations, and fund large relative value positions. Thus we divide the Funding factors into three components: (i) Unsecured Funding (OIS spread), (ii) Secured Funding (MBS spread) and (iii) Commercial Paper (CP). Following the Lehman bankruptcy, there were large and persistent shocks to all these funding factors. These traditional funding sources for most financial institutions dried up almost instantly, and the Federal Reserve decided to intervene in funding markets by means of swap lines and MBS and CP direct purchases. Before linking the behavior of these funding markets and the LtA, it is useful to summarize the behavior of these determinants and their correlations with LtA in each given sub-period.

- The characteristics of the unsecured funding market is captured by the spread between 3-month LIBOR and 3-month US Overnight Index Swap (OIS) rates. A rise in the differential implies that financial institutions become less willing to lend to each other due to problems in creditworthiness. We label this proxy as UNSECUREDF. Figure 4 suggests that its average and volatility increase monotonically from pre-crisis to credit crisis periods, displaying a $61 \%$ correlation with LtA during the latter period. The differential tends to close during the after-crisis, though still with higher volatility and correlation values compared to both the pre-crisis and liquidity crisis periods.

\section{[Insert Figure 4 Here]}

- The characteristics of the secured funding market is captured by the spread between US Treasury repo rates and US Agency Mortgage-Backed Security (MBS) rates. This spread captures the difference in value between high-quality collateral vs. low quality collateral securities. Gabaix et al. (2007) argue that the MBS markets plays an important funding role, and may affect limits to arbitrage. An increase in the MBS spread signals an increase in the risk premium related to collateral value, affecting the ability to leverage risky-arbitrage positions. This can be treated synonymously as the leverage constraints of Gromb and Vayanos (2010). Moreover, Sarkar and Shrader (2010) argue that this is a good proxy for funding illiquidity, and that if the secured funding is indeed stressed, it is likely that the unsecured funding will also be in trouble. We label this proxy as SECUREDF. Similar to the previous funding cost, Figure 5 reveals that SECUREDF also increases monotonically from the pre-crisis to the credit crisis in terms of average, volatility and correlation with LtA. The correlation with LtA is $63 \%$ during the credit turmoil.

\section{[Insert Figure 5 Here]}

- The third component is the commercial paper (CP) issuance. The majority of commercial papers are issued by the financial sector in order to raise cheap capital at short-term interest rates. Under normal market conditions, interest rates on commercial paper have been historically just slightly higher than those on Treasury bills and lower than LIBOR. Before the crisis, market players regarded most CP of major financial institutions as a high-quality safe asset. Figure 6 reveals that CP tends 
to decrease from pre-crisis to credit crisis in terms of average, volatility and correlation with LtA. The correlation with LtA is $47 \%$ during the credit crisis phase.

[Insert Figure 6 Here]

\section{Global Macro Factors}

- Macro-Activity Risk: We extract an index of macroeconomic activity using Ludvigson and Ng (2009) approach. They use dynamic factor analysis to estimate a set of common factors from a panel of 132 real, nominal, and monetary measures of economic activity. They show that such a procedure to synthesize information from macroeconomic activity possesses strong predictive content for excess bond returns, explaining $26 \%$ of the one-year-ahead variation in returns, and importantly, contain information that is unspanned by bond yields. They argue that part of the success of using this procedure depends on crosssectional averaging that irons out temporal instabilities that may be present in individual series. This allows to better isolate the characteristics related to marginal utilities, which are more directly linked to the factors that must be common across a large panel of economic fundamentals. Their findings suggest that macro fundamentals (i.e. real and inflation factors) do carry significance information to explain expected excess returns in the sovereign bond market. Unlike Ludvigson and Ng, however, we exclude price based information from the panel in order to interpret this variable as a pure macro factor and allow for an easier distinction between macro-activity and the other risk factors. After removing price based information from the panel we end up with a 102 cross-sectional units. ${ }^{19}$ We label this factor as the LN-Macro factor. The conjecture is that deteriorating macroeconomic conditions can create constraints on financial institutions, ultimately affecting limits to arbitrage.

- Term Premia: Diebold and Li (2006) show that slope factor of the US yield curve is closely related to macroeconomic activity (capacity utilization). It has also been argued that arbitrageurs fund their activities using short maturity instruments, often rolling overnight positions. ${ }^{20}$ Vayanos and Vila (2009) study a theoretical model in which investors have preferences for long maturity bonds, while arbitrageurs can move along the term structure, and are able to invest in all maturities and incorporate information (about current and future short rates) into bond prices. Following a demand shock, arbitrageurs take advantage of this opportunity by shorting (and longing) specific bonds across the term structure, accordingly. Following this argument, the slope of the term structure is informative about the relative cost of arbitrageurs to fund risky arbitrage. We define the US slope as the difference between 10 year Treasury bonds and 3 month LIBOR yields, and label it as USD Slope factor.

- Equity Risk Premium Factor: A vast macro-finance literature find evidence of predictability in asset prices. Campbell and Cochrane (1999) motivate the findings in the context of a model with time-varying risk aversion due to habit persistence. Bansal and Yaron (2005) argue that a significant component of predictability is due to a pure cash-flow channel when shocks to cash flows are very persistent, and utilities display a preference for early resolution of uncertainty (Epstein-Zin). In both cases, dividend yields have predictive power for future expected excess returns. Thus, we use the weekly S\&P500 dividend yield to control for hidden priced state variables that may affect market-wide expected returns.

\section{Local Risk Factors}

\footnotetext{
${ }^{19}$ Examples of price variables removed include: S\&P dividend yield, the Federal Funds (FF) rate; 10 year T-bond; 10 year - FF term spread; Baa - FF default spread; and the Dollar-Yen exchange rate.

${ }^{20}$ Litterman and Scheinkman (1991) argue that the term structure slope drives a significant portion of interest rates.
} 
- Local Equity and Credit Index: To measure the impact of Emerging market equity indices on the LtA, we use MSCI Emerging Market index. ${ }^{21}$. We also use Markit CDX Emerging Markets Index to see the impact of credit default swaps. ${ }^{22}$

\section{Global Sentiment Factors}

- Sentiment Risk: A large body of empirical literature argues that investors' sentiment matters for asset prices. De Long et al. (1990) classify investors as sentiment-free arbitrageurs and sentiment-driven traders, arguing that sentiment-based demand shocks cause mispricings, affecting arbitrage attractiveness. As a top-down approach, Baker and Wurgler (2007) propose an index of Sentiment that quantifies the behavior of investors in stock markets. This index is based on the first principal component of five stock market indicators: closed-end fund discount, trading volume, dividend premium, IPOs, new stock issues. We build on their insight but create a new sentiment index by removing information that may be more linked to fundamentals rather than sentiment. We compute the first principal component of the weighted average closed-end funds discount ${ }^{23}$ of the four largest US Emerging Market debt funds (EDD, TEI, ESD and MSD) and the trading volume on the New York Stock Exchange (NYSE). ${ }^{24}$ See also Bodurtha et al. (1995) who argue that closed-end fund discount is linked to market sentiment. Baker and Stein (2004) suggest that in presence of short-sale constraints, high trading volume is a sign of overvaluation (rise of investor sentiment) and investor irrationality. Figure 7 reveals that Sentiment rises to its highest average and volatility levels during the credit crisis, having a correlation of $43 \%$ with LtA.

- Perceived Tail Event Risk: One way to measure the perception of tail event risk is by VIX index, a weighted average of implied volatilities of options with different strikes written on the $S \& P 500$ index with 30 days maturity. It summarizes the cost of protection against major market tail event risk. Pan and Singleton (2008) use VIX as a measure of tail event risk in credit markets, and argue that it is an important proxy of investors' appetite against risky assets. They show that EM risk premiums (i.e. Turkey and Mexico) are highly sensitive to US stock market volatility (VIX). Further examples include Campbell and Taksler (2003), who find significant co-movement between firm-implied volatility and credit risk premiums. Similarly, Landschoot (2008) highlights the significance of VIX (and VIXsquared to capture non-linearity effects) in corporate credit premiums across two currencies (i.e. usd and euro). Finally, Cremers et al. (2008) use option-implied volatility as a proxy for the jump risk premium and document its importance for credit spreads. ${ }^{25}$ Based on these arguments, we use both the first difference of VIX and the difference in VIX-squared values as proxies of perceived tail event risk. Figure 8 summarizes the results: VIX level and volatility peaked during the credit crisis. What is of

\footnotetext{
${ }^{21}$ MSCI Emerging Market index is generated by Morgan Stanley Capital International (MSCI). As of May 2005, the index consists of twenty-six Emerging Market indices: Argentina, Brazil, Chile, Colombia, Mexico, Peru, Venezuela, China, India, Indonesia, Korea, Malaysia, Pakistan, Philippines, Russia, Taiwan, Thailand, Egypt, Israel, Jordan, Morocco, Czech Republic, Hungary, Poland, Turkey and South Africa

${ }^{22} \mathrm{CDX}$ index is determined by a consortium of sixteen member banks to measure the credit quality of Emerging Markets

${ }^{23}$ Closed-end funds issue a fixed number of shares that later trade on stock markets. A closed-end fund premium (discount) is how much greater (smaller) the fund's market price is compared to its net asset value (NAV). We generate the corresponding premiums (discounts) by dividing market prices to NAVs. The closed-end fund index is created accordingly as the weighted average of the premiums (discounts), based on the market capitalization of the related closed-end funds.

${ }^{24} \mathrm{EDD}$ has a market cap of 1189 million usd and it is managed by Morgan Stanley Emerging Markets. TEI, having a market cap of 772 million usd, stands for Templeton Emerging Markets Income Fund. ESD, having a market cap of 580 million usd, stands for Legg Mason Partners Income Trust - Western Asset Emerging Markets Debt Portfolio. Finally, MSD, having a market cap of 235 million usd, stands for Morgan Stanley Emerging Markets Debt Fund Inc.

${ }^{25}$ Refer to Buraschi and Jiltsov (2006), who show theoretically that the implied volatility of index options are driven by disagreement in beliefs.
} 
particular interest given our focus, however, is that the correlation with LtA rise from $15 \%$ during the pre-crisis period to $67 \%$ in credit crisis period.

\section{Global Uncertainty Factor}

- Subjective Uncertainty Factors: Starting from Knight (1921), part of the literature claims that asset prices reflect both risk and uncertainty. While the former is defined in terms of measurable quantity that directly affects realized marginal utility in equilibrium (i.e. known unknowns), the latter refers to the effect of unmeasurable quantities (i.e. unknown unknowns). Gilboa and Schmeidler (1989), Epstein and Wang (1994) and Epstein and Schneider (2008) investigate examples of single agents economies with multiple priors. A different approach is studied by Buraschi and Jiltsov (2006) and Buraschi et al. (2009) that investigate economies with multiple agents with heterogeneous beliefs. ${ }^{26}$ In their paper, credit spreads are linked to a systemic component in the heterogeneous perceptions of agents, and they document a remarkable relationship between credit spreads and differences in beliefs. ${ }^{27}$ Similarly, Beber et al. (2010) find that differences in beliefs help to explain implied volatilities in the foreign exchange market. In a similar line of research, Caballero and Krishnamurthy (2008) model how an increase in Knightian uncertainty can trigger an increase in investor risk-aversion and demand for liquid assets. Furthermore, Bloom (2009) introduces a structural framework to investigate the impact of objective uncertainty shocks, which jump up after major crisis events. In our context, we incorporate subjective uncertainty via the DIB factor, constructed as in Buraschi and Jiltsov (2006). Then, we document the extent to which subjective belief heterogeneity is linked to changes in the LtA.

\section{Methodology}

We adopt a static approach to construct the term structure of yields and credit spreads to avoid imposing modeling assumptions on the dynamics of interest rates or default risk that may affect the results. To improve robustness, given the large scale dimension of the problem (two risk-free and two credit spread term structures), we follow Houweling et al. (2001) and use a joint estimation methodology. Instead of deriving spread curves by subtracting risk-free yields from risky yields, in this estimation method the two sets of parameters of the risk-free term structure and the credit risk premium curve are jointly estimated from a combined data set of bonds. This reduces the dimensionality of the problem and makes the results more robust. ${ }^{28}$

The US risk-free curve is estimated with 6-12 month London Interbank Offer Rates (LIBOR) at the shortend, and 1-30 year maturity US swap rates at the long end. The EU risk-free curve is estimated with 6-12 month Euro Interbank Offer Rates (EURIBOR) for short-end, and 1-30 year maturity euro swap rates for long-end of the term structure. ${ }^{29}$ The risk-free curves are modeled as Svensson (1994) functions (each with six parameters) and the credit risk premium curves are modeled as Nelson-Siegel functions (each with four parameters), as discussed in Nelson and Siegel (1987).

\section{Panel Regressions}

\footnotetext{
${ }^{26}$ They generate an Uncertainty-DiB factor by de-trending the first principal component of the differentials in the future earningforecasts of several US firms.

${ }^{27}$ See also Detemple and Murthy (1994) and Basak, S. (2000) for markets with heterogeneous beliefs.

${ }^{28}$ For a detailed discussion of alternative static spline models, see McCulloch (1971, 1975), Vasicek and Fong (1982), Rice and Rosenblatt (1983), Shea (1985) and Nychka (1995).

${ }^{29}$ The details of the model are available from the authors upon request.
} 
Given the two credit spread curves, we estimate three-equation fixed-effects panel regressions on each maturity and each subsample. Because of the potential persistence in the spreads, all regressions are run in differences: The independent variable is the first-difference of the absolute LtA, and the dependent variables are the first-differences of the potential determinants discussed in Section $4 .{ }^{30}$ In order to capture the meanreverting property of LtA, we also included the first lagged variables, which also shed light on the autocorrelated nature of the LtA fluctuations. In the fixed effects model we assume that intercepts represent country-specific shifts. As Nickell (1981) points out, fixed-effects model may suffer from statistical biases when the number of individuals are greater than time periods. In our context, the number of individual variables never exceeds the time length, so our methodology should not suffer from this drawback. ${ }^{31}$

\section{Price Discovery}

Eq. (7) suggests that a single issuer's credit spreads across two currencies can be linked by a simple arbitrage relation. Having observed that there exists an empirical difference between the two spreads, a natural question then arises: how can the financial markets persist in pricing usd credit risks differently than their euro equivalents? Although our main interest is to investigate macro level determinants of persistent deviations from the equilibrium, there might also be micro-structural factors (i.e. the natural habitat of arbitrageurs, the location of traders, the funding currency of trading operations). This leads to an investigation of the differences of the information contents of credit risks across currencies. As discussed previously, the EM bonds denominated in two currencies can be treated as two homogeneous assets. Given that the risk premiums are not identical, it becomes interesting to evaluate (a) whether a bond in one currency provides a more timely information than its equivalent in the other currency and (b) how this result relates to the properties of the LtA. In other words, we seek to understand which bond retains a greater contribution to price discovery. As defined by Lehmann (2002), price discovery can be described as timely incorporation of the trading activities into market prices. If usd and euro Emerging Markets bonds were trading in one market place, the price discovery would take place in one single market. However we know that these bonds are traded in multiple regions, mainly in Eurozone and USA. Since the order flow of the Eurobonds are fragmented, the price discovery would be split among these markets.

There are two popular ways to conduct price discovery analysis, namely information share (IS) measure suggested by Hasbrouck (1995) and component share (CS) measure suggested by Gonzalo and Granger (1995). Both measures rely on the vector error-correction models (VECM) of market prices. IS assumes that price volatility reflects new information, and it allows for the correlation among multiple markets via the variance and covariance of price innovations. Following Blanco et al. (2005), we calculate the IS measures to find the contribution of usd credit risk premiums to euro credit risk premiums. It is necessary to run VECM to carry out this analysis. First, we test for the cointegration between the corresponding credit spreads to see if VECM can be applied. ${ }^{32}$ We conduct this analysis for the entire period and not for each sub-sample period. The reasoning lies in the fact that we wish to observe a long-term price discovery relationship among bonds. Furthermore, the sample size becomes considerably reduced when sub-samples are concerned independently, and the argument

\footnotetext{
${ }^{30}$ We use the absolute LtA rather than original LtA to facilitate the interpretation of the signs of the slope coefficients.

${ }^{31}$ In this paper, we did not use random-effects model. As Hausman (1978) points out, the random effects model assumes independence between the individual effect and the independent variables. If this assumption is violated, random effects estimator is inconsistent and biased. On the other hand, fixed effects estimator does not suffer from such failure of orthogonality. See Maddala (1971) and Mundlak (1978) for the issue of specification. In addition, see Nerlove and Balestra (1966) for he bias and efficiency of the estimators in random and fixed models.

${ }^{32}$ For cointegration, we used Johansen's cointegration test, proposed by Johansen (1988), and we determined the number of lags according to the Akaike information criterion.
} 
of long-term relationship no longer becomes valid. ${ }^{33}$ Having observed that cointegration exists, we run the VECM shown in Table 7 with the given coefficients A1 and A2. If it is the euro risk premium that retains the significant contribution to the price discovery, then A1 should be statistically significant. Similarly, if usd risk premium has the significant contribution, then A2 should be statistically significant. If both coefficients are significant, then the two risk premiums have significant contribution to the price discovery. The contribution of the usd risk premium to price discovery is defined by the Hasbrouck measures specified in Table 7. Given that Hasbrouck's measures can provide only upper and lower bounds, Baillie et al. (2002) suggest using averages of these bounds. If the average of Hasbrouck bounds is greater (less) than 0.5 then usd (euro) risk premium leads euro (usd) risk premium.

\section{Results}

The LtA is highly time-varying and state-dependent. In the pre-crisis period, it is insignificantly different from zero, but it becomes large and extremely volatile during the crisis, suggesting a limited arbitrageur participation in these sovereign bond markets. This is especially acute during the credit crisis, which includes the Lehman collapse. The most striking feature of LtA during this period is its persistence. In the after-crisis period, LtA gradually converges back to the levels seen during the liquidity crisis sub-period. The volatility of LtA is, however, quite volatile. Some natural questions emerge: What are the most important explanatory factors that help to explain the dynamics and persistence of LtA during the crisis? Given the unconventional policy measures that both the Federal Reserve and the U.S. Treasury implemented, what are the initiatives that later allowed LtA to converge back to its initial levels? Which initiatives did not have effect? What is the extent to which the dynamics of LtA was driven by shocks to fundamentals (i.e. real economic activity) as opposed to funding factors, sentiment, perception of tail risk, and uncertainty. If funding factors played a role, which one of the funding markets played a more significant role (unsecured swap market, secured funding markets, commercial paper)?

What happened after the crisis is a difficult issue to resolve. The equilibrium implications may be related to the interventions of the U.S. and European Governments or simply to an improvement of the economic fundamentals. Traditional asset pricing models often make it difficult to address these questions given that equilibria are traditionally assumed to be Pareto optimal. We will explore these questions empirically. Given the vast empirical finance literature that studies the asset pricing implications of both cash flow and discount factor (beta) risk, we organize our explanatory variables related to shocks to macro fundamentals in two main groups. In the first group, we consider those factors representing cash-flow risk, such as LN-Macro; in the second group, we consider factors that are more directly related to discount factor risk: the Equity Risk Premium factors, Percieved Tail Event Risk, and Subjective Uncertainty factors.

\section{Panel Regressions}

In all panels, lagged LtA is statistically very significant with negative slope coefficients, indicating that the process is persistent and mean-reverting. In the pre-crisis period, the slope coefficient is about $-0.36 \%$ and it becomes $-0.50 \%$ during the crisis and after-crisis, indicating stronger mean-reversion during the market turmoil. With regards to the economic explanatory variables, we find that in three different periods (i.e. pre-crisis, crisis or after-crisis) the dynamics of LtA is explained by different groups of explanatory variables.

\footnotetext{
${ }^{33}$ It should still be pointed out that the entire sample period obviously covers major structural breaks. This may affect our results. We repeated the analysis and computed Hasbrouck's measures independently for each three sub-samples as well. We find that results that hold for the entire period holds to a great extent also for each sub-sample.
} 
We also find that bond maturity plays an important role: bonds with different maturities have different sensitivities to different risk factors. Furthermore, our results show evidence that risk premiums are mainly driven by U.S. risk factors. This finds support also in Longstaff et al. (2008), who argue that credit risk premiums of major EM are less sensitive to local economic factors than they are to U.S. stock and global bond markets.

[Insert Table 5 here]

1. Pre-Crisis Period: As shown in Table $5, R^{2}$ values during the pre-crisis period range from $19 \%$ to $25 \%$. The findings suggest that during this period, the economic explanatory variables, even when significant, have low statistical powers. The best predictor of future $L t A$ is simply the lagged value of the $L t A$. Perceived Tail Event Risk is found insignificant for all maturity buckets, whereas the Secured Funding and Sentiment Risk are found statistically significant only for the 1-3 year maturity. Furthermore, the Friction factor for Brazil (i.e bid-ask spreads) is found significant for all maturities, except for the longest end of the term structure. ${ }^{34}$ Nevertheless, the same pattern is not observed for Mexico and Turkey, which makes it relatively difficult to generalize that bond-specific illiquidity is a consistently dominant factor in the cross-sectional variations in LtA. Interestingly, the subjective uncertainty factor (i.e. DiB) is found strongly significant for 1-3 and 3-6 year maturities and dividend yield is found significant for 3-6 and 6-9 year maturities. In fact, Figure 9 displays that Global Funding Risk has the highest marginal contribution to LtA in pre-crisis, specifically for the very short-end of the term structure. Nonetheless, it should be noticed that the explanatory powers of all variables are very low, suggesting that apart from lagged values of LtA, none of the market risk factors are relevant. This does not come as a surprise, given that LtA values are already approximately zero during this period.

2. Crisis Period: A completely different picture emerges during the crisis period (i.e. 9 August 2007 31 March 2009). The explanatory power of the model is considerably higher, with $R^{2}$ values ranging from $25 \%$ to $53 \%$. The average value of $L t A$ widens and fluctuates considerably throughout the period. Similar to the pre-crises period, for the short end of the curve, apart from lagged $L t A$, the most significant variables are secured funding and the Subjective Uncertainty factor. On the other hand, the impact of Global Sentiment (behavioral biases), Perceived Tail Event Risk and Funding costs become highly important for longer-term maturities, consistent with the argument in Vayanos and Vila (2009), where demand shocks located at longer ends of the term structure generate larger impacts for risk averse arbitrageurs, who are funding their operations using short-end instruments. According to Figure 9, Global Sentiment and the Global Funding Risk factors have the highest marginal contributions on $L t A$, providing supporting evidence that arbitrage deviations can indeed be affected by sentiment risk (behavioral irrationality), perception of rare events risk and the funding constraints. The impact of funding risks (including the leverage constraints) is an empirical validation of Gromb and Vayanos (2010). This finding is also related to Hart and Moore (1995), where agents' ability to borrow is adversely affected by the uncertainty of assets' liquidation. Moreover, the effect of Tail Event Risk is consistent with the findings in Pan and Singleton (2008), who find high correlation between VIX and sovereign risk premiums (including Mexico and Turkey), arguing that VIX is a critical measure of an investor's appetite against tail event risk exposures.

[Insert Figure 9 here]

\footnotetext{
${ }^{34}$ We also used bond-specific trading volumes and found them to be insignificant in all periods.
} 
Perhaps surprisingly, the Unsecured Funding risk factor is found statistically insignificant. This comes as a surprise to us, given the extensive debate during the crisis that focused on this issue and that induced the Federal Reserve to intervene and address directly the wide levels of the LIBOR/OIS spread in the unsecured interbank market. On the other hand, the impact of the spread between Mortgage-Backed Securities (MBS) and Treasury repo rates, which is a proxy for the liquidity in the secured funding market by comparing highly-liquid vs. less liquid collateral, is significant. The stressed value of these spreads have been recognized by the Federal Reserve, which eventually intervened at the end of 2008 with a significant program of MBS purchases. ${ }^{35}$ This finding is also consistent with the work of Bernanke and Gertler (1989) that suggest that collateral values can be severely impaired in case of negative shocks to economic activity, and can play a role on the efficient allocation of capital. An increase in sentiment risk, high market implied volatility, and rising funding costs with less-than-liquid instruments increases limits to arbitrage. An additional interesting finding relates to the role of dividend yields, which are found statistically significant for the 9-15 year bonds, supporting the argument that predictability is indeed driven by a latent risk factor affecting the price of risk. The long run bonds, as opposed to their short-term equivalents, are more sensitive to this risk factor. On the other hand, the Term Premia and bond-specific Friction factors have a negligible impact.

[Insert Table 6 here]

When the crisis period is divided into two further sub-samples, namely the liquidity and credit crises, respectively, interesting results emerge. Table 6 reveals that during the liquidity crisis, $R^{2}$ range between $23 \%$ and $30 \%$, which is slightly higher than in the pre-crisis period, but much smaller than compared to the credit crisis sub-period. The CP (commercial paper) factor is found strongly significant for 13 year bonds. This is interesting, because while the commercial papers of large financial institutions were regarded as short-term, safe-debt instruments, this perception changed with the collapse of Bearn Stearn's two hedge fund on 31 July 2007 and the suspension of BNP Paribas's three investment vehicle on 7 August 2007. Commercial papers were widely used as collaterals by these investment banks, and money market participants became increasingly reluctant to buy these assets. The lack of liquidity in the money market reached a point that convinced the Federal Reserve to directly purchase commercial paper for the first time in its history.

During the second phase of the two sub-periods (i.e. credit crisis), following the Lehman collapse, the $R^{2}$ increases dramatically up to $76 \%$ for the long-end of the term structure. As displayed in Figure 9, the most important explanatory variable is the Global Sentiment, explaining about $18 \%-25 \%$ of the total variation of LtA for longer term maturities. It is then followed by Global Funding and Global Macro risk factors, explaining between $12 \%-16 \%$, and $4 \%-16 \%$, respectively, of the total variation of the $L t A$ of longer maturity bonds. On average, the marginal contribution of Perceived Tail Event Risk and Friction factors rise with the maturity of the bond, suggesting that the long-end of the term structure is comparably more sensitive to hedging risk and liquidity constraints. It should be noticed that the Global Macro factor is more relevant for longer maturity bonds (9-15 years): in this section of the term structure, it has the second largest impact (after Global Sentiment). This confirms that long-term bonds are comparably more sensitive to macro fundamentals. This finding is quite interesting since it shows us that not only the funding conditions but also the deteriorating macroeconomic conditions emanating from

\footnotetext{
${ }^{35}$ Sarkar and Shrader (2010) study the behavior of the Secured funding factor as a proxy for funding illiquidity and the impact of the FED asset purchase programs.
} 
U.S can create constraints on financial institutions, ultimately affecting limits to arbitrage. According to International Monetary Fund (2008) most of the developed and emerging markets experienced a massive decline in world trade activity of about $30 \%$. This might be due to the rising counterparty risk in financial markets, which significantly reduced the trade credit to support import and export. On the other hand, the impact of Global Funding retains a higher marginal relevance than the Global Macro risks for 6-9 years maturities. This suggests that there is an interplay between these two variables, and that the ranking of their marginal impact depends on the bond maturity. Furthermore, the Subjective Uncertainty factor (i.e. DiB) is also found statistically significant all maturities (except 6-9 years), providing evidence in support of the findings in Buraschi and Jiltsov (2006), with regards to the impact of heterogeneous belief. It might be noticed that LN-Macro, Equity Risk Premium, Percieved Tail Event Risk and Subjective Uncertainty factors all have significant explanatory power for the dynamics of $L t A$, thus suggesting that both the cash-flow and discount-rate factors are almost equally important.

3. After-Crisis Period: As for the after-crisis period, the $R^{2}$ drops considerably compared to the previous periods, ranging from $22 \%$ to $44 \%$. The contribution is mostly due to Local Risk factors (i.e. EM-CDSI), which is statistically significant for all maturities, except for the 3-6 years. Dividend yields are once again economically relevant only for the 9-15 year maturities, validating that changes in the price of risk can affect $L t A$. Nonetheless, the explanatory power of these shocks are limited, implying that Eurobond markets are in the process of stabilizing.

\section{Social Welfare and Policy Implications}

It is possible to think the Federal Reserve interventions in the financial markets in three major phases: Liquidity Phase, Credit Phase and Uncertainty Phase. In the first phase, the Federal Reserve was concerned with the provision of liquidity to local and international markets via injection of capital to US banks and extension of global swap lines. The main goal was to reduce balance sheet constraints through Central Bank monetary easing. At this stage, the Federal Reserve developed a new policy to extend liquidity directly to borrowers and investors in central credit markets. According to Bernanke (2009), the Federal Reserve also attempted to reduce roll-over risk via financing bank purchases of commercial papers from money market mutual funds. In the second phase, the Federal Reserve started to address credit risk concerns via purchases of mortgage-backed securities, given that liquidity provision failed to solve the problem fully. This means that even though the level of liquidity had been sufficient, uncertainty over asset quality, capital and credit risk continued to impair the lending activities of financial intermediaries. In the third phase, which is quite different compared to phase 1 or 2 or any previous historical experience, the Federal Reserve addressed more directly market uncertainty and tail risk perception by implementing explicit stress tests on a broad set of banks and financial institutions. From our results, we observe that the elimination of LtA coincided with the third phase.

During these three phases, the Federal Reserves took unconventional measures to address the functioning of the financial markets. It is interesting to explore which of these measures had the largest effects on $L t A$ : (1) On 3 October 2008, U.S. Treasury launched the Troubled Asset Relief Program (TARP), which involved the mass purchasing of capital and equity (approximately 700 billion usd) of US commercial banks. ${ }^{36}$ (2) On

\footnotetext{
${ }^{36}$ The US Treasury managed to inject capital into more than 600 US banks under TARP program. US banks demanded a total of 313.4 billion usd worth of fund, and the Fed fulfilled $99 \%$ of it by injecting 308.9 billion usd. More than half of this rescue package (176.3 billion usd) was distributed to seven major US financial institutions: Citigroup, Bank of America, Wells Fargo, JP Morgan, GMAC, Goldman Sachs and Morgan Stanley. According to Bloomberg calculations, approximately 192.3 billion usd of the bailout amount has been paid back to the US Government, which now has an estimated investment return exceeding 25 billion usd. Citigroup bailout yielded the biggest return on investment, totaling 8.2 billion usd. Out of 45 billion, 11 billion usd is still to be paid back.
} 
26 October 2008, the Federal Reserve started to purchase commercial papers directly from money markets. By January 2009, the FED was the largest single buyer of commercial papers, absorbing $22 \%$ of issuance worth of 350 billion usd. (3) On 25 November 2008, the Federal Reserve announced the Term Asset-Backed Securities Loan Facility (TALF), which involved the lending of 200 billion usd repo loans for the collaterals of newly issued asset-backed securities. (4) The Federal Reserve extended global swap lines to meet the usd demand. Twelve new Central Banks around the world were included in this program on 10 December 2008, the total amount growing from 24 to 620 billion usd. ${ }^{37}$

Within the context of the second initiative, towards the end of 2008 the Federal Reserve purchased a total of 400 billion usd worth of mortgage-backed securities issued by government-sponsored enterprises (GSEs). By the end of the first quarter 2010, this amount totaled up to 1.3 trillion usd. During the third phase of policy interventions, the Federal Reserve Chairman Bernanke made public announcements and conducted direct financial assessments of major US banks on 25 February 2009, releasing a set of stress test results on 5 May 2009. The goal of this exercise was to reduce uncertainty about the true fundamental value of the major financial institutions and regain the trust of market participants. To highlight the positive assessment results, Bernanke pointed out to the Joint Economic Committee: 'I've looked at many of the banks and I believe that many of them will be able to meet their capital needs without further government capital. ${ }^{38}$

As Krishnamurthy (2010) highlights, with the disappearance of arbitrageurs, the Federal Reserve stepped in aggressively into picture in late 2008, effectively replacing arbitrageurs in their function of providing liquidity to markets and driving prices back to fundamentals. The main goal was to inject capital, lower interest rates, increase liquidity, encourage private lending, remove toxic assets (from the balance sheets of financial institutions) and relieve the burden of financial uncertainty. In the end, it was hoped that the general level of risk-aversion would fall. More specifically, TARP aimed at compensating for the lost capital of US banks and rejuvenating their lending activities. TALF aimed at reviving the credit activities in the economy via encouraging the issuance of low-interest asset-backed securities. The Global Swap Lines was an effort to fulfill the foreign usd liquidity demand at a global level. The MBS purchasing program was designed to liberate financial institutions from assets that traded way below their fundamental values because of collateral constraints and funding risks.

Our study highlights that LtA reached its maximum level of 491 basis points during November 2008 regardless of the initiation of the TARP and TALF programs. A gradual convergence to equilibrium starts much later. ${ }^{39}$ It coincides with the MBS purchases program that starts to take place in the first quarter of 2009. Afterward, the gap between the market and fundamental prices of mortgage-backed securities diminished considerably. Recalling that the Secured funding risk factor is a highly significant explanatory variable during the two phases of the crisis, we find that MBS-Treasury repo spreads are no longer significant in explaining the dynamics of LtA after April 2009. Similar to our findings, Dooley and Hutchison (2009) analyze the impact of various types of news from US to emerging markets during the crises period of time, and find that news announcements about substantial expansion of the U.S. Treasury's balance sheet by the FED programs significantly reduced credit default swap (CDS) spreads of Brazil, Mexico and Turkey. This points out to the importance of Secured funding in the functioning of financial markets, and in the funding activity of

\footnotetext{
${ }^{37}$ Banco Central do Brasil, Banco de Mexico, Bank of England, European Central Bank, Swiss National Bank, Danmarks Nationalbank, Norges Bank, Sveriges Riksbank, Bank of Japan, Bank of Korea, Monetary Authority of Singapore, Reserve Bank of Australia, Reserve Bank of New Zealand and Bank of Canada.

${ }^{38}$ This quotation is taken from Reuters News Agency on May 5, 2009.

${ }^{39}$ It should be noted that Turkey reaches its minimum value of LtA before Mexico and Brazil. In addition, for the given three countries, it is a norm that the LtA in long-term bonds reach their minimum values considerably slower than their short-term equivalents, validating the sensitivity of long-term bonds.
} 
arbitrageurs. At this stage, most US banks began increasing their lending activities, thus relieving prevailing market frictions. In accordance with Gromb and Vayanos (2010), where arbitrageurs tend to collateralize their positions, we observe initially that the impairment in collateral values prevented wide arbitrageurs participation.

While the Fed intervention in mortgage-backed markets indeed helped unlocking secured credit markets, we find that this step has certainly not been sufficient. Perception of Tail Event Risk (proxy by VIX) was still very significant at the beginning of the second phase of the Government program. We needed to wait until the announcement of the stress tests to see a recompression of LtA. The impact of the Perceived Tail Event Risk factor is completely eliminated after the stress test announcements, which suggest that it has been successful in quickly reducing subjective uncertainty. Based on our results, we find that the initial interventions had been ineffective to help $L t A$ compression. ${ }^{40}$ The following measures, however, helped $L t A$ values to converge back to their pre-crisis levels. ${ }^{41}$

To summarize, the theory of Limits to Arbitrage is an important stream of literature that can help our understanding of certain financial market anomalies. Our investigation on the dynamic properties of the limits to arbitrage around a period of market distress shows what type of roles the public policies and market interventions can (or cannot) play. As argued by Bernarke (2009), the Federal Reserve intervened via asset purchase programs and as a lender of last resort, when financial markets were illiquid and impaired by balance sheet constraints. Vast amount of government resources have been used to help the financial sector: this has strong social and welfare implications. Not all these measures, however, have been as successful as hoped.

\section{Price Discovery}

The apparent arbitrage opportunities in the distressed markets, which give rise to the risks discussed earlier on, can be either persistent and survive in the long-run, or still be essentially a short-term phenomenon. To investigate this question, we run a cointegration analysis. We find that both the usd and euro risk premiums are found to be cointegrated for each bond pair during the whole sample period. The corresponding risk premiums are also found highly cointegarted during each sub-sample period, including the credit crisis. ${ }^{42}$ This is interesting since it shows that the no-arbitrage deviations that we discussed earlier are short-term in nature even during particularly stressed period of time. A natural question, however, emerges: Is there a consistent lead/lag relation across these bonds? Is price discovery usually faster in the usd market so that usd risk premium leads the equivalent in euro? Are there persistent characteristics in the lead/lag relationships between the bond issued by the same issuer but denominated in different currencies? Similar to Blanco et al. (2005) we conduct the price discovery analysis via Hasbrouck's IS measure to investigate the dynamic behavior of price of euro and usd credit spreads. We report upper, lower and averages of Hasbrouck bounds in Table 7. Our findings reveal that for Brazilian and Mexican bonds the A2 coefficients are positive and statistically significant, implying that the usd-denominated bonds strictly lead their euro-denominated equivalents in terms of price discovery. For Turkey, however, the opposite pattern emerges: A1 coefficient is negative and statistically significant, implying that the euro-denominated bonds significantly contribute more than their usd-denominated equivalents in all maturity buckets. Taking into account all maturities available, we find that the contributions of usd-denominated bonds, on average, are $67 \%$ and $66 \%$ for Brazil and Mexico, respectively, and $34 \%$ for Turkey. This result seems linked to a previous cross-section pattern: the euro risk premiums are

\footnotetext{
${ }^{40}$ In a different context and using different methods, Taylor and Williams (2009) finds support to this result and find no evidence validating the success of TAF in reducing the Libor-OIS spreads.

${ }^{41}$ See also McAndrews et al. 2008, Christensen et al. 2009, Goldberg et al. 2010.

${ }^{42}$ Correlations are consistently higher among the same maturity groups, though in case of Mexico, the relationship among different maturity groups tend to become stronger as maturities increase.
} 
more volatile than their usd equivalents in Mexico and Brazil, regardless of the period; the exact opposite pattern is observed in Turkey. Consistent with Table 2, this also implies that the risk premiums having the lead in price discovery maintain also the least volatility.

\section{[Insert Table 7 here]}

These findings suggest that the price discovery in Emerging Market bonds may be regional, or specific to the natural habitat of traders. This also shows that the nature of the reference-funding market is important in defining the currency in which price discovery occurs. In the case of Turkey, the majority of the market-making activity is funded in euro and conducted by European banks. The opposite holds for Brazil and Mexico. This might have important implications for LtA. For instance, a European hedge fund may have a preferred habitat in the euro-specific region. However, due to his natural habitat, he/she may have limited access to usd (or even euro) during times of crisis, which would in turn generate a demand/supply shock in the market. Knowing that capital is less available to the investor during the crisis period of time, arbitrageur would also avoid the transaction, and hence the LtA distortion. Gromb and Vayanos (2002) formalize this by showing that if the arbitrageurs lack the sufficient capital to cover the variations in both margin accounts of the segmented asset markets, then they might not be able to eliminate the price discrepancies.

\section{Conclusion}

We contribute to the existing literature by introducing an empirical notion of limits to arbitrage (LtA) in the context of Emerging Markets during the credit crisis, and investigating its determinants. We study the role of sentiment risk, macro-fundamental risks, uncertainty, funding and liquidity costs on the willingness of agent to act on near arbitrage opportunities. First, it is proven that under no-arbitrage condition, the LtA proxy should be zero. Our findings suggest, however, that LtA is time-varying and state dependent. While it is close to zero during pre-crisis, it becomes large and volatile during the market turmoil, and tends to converge back to initial levels during the after-crisis. This suggests that while arbitrageurs were able (or willing) to take positions in stable pre-crisis period, their risk-aversion or funding abilities prevented them from providing liquidity to the market during the crisis, and driving asset prices back to fundamentals. In the end, since LtA displays fundamental characteristics in pre-crisis, and behavioral biases in crisis periods, it can be argued that for the corresponding bond markets, we find evidence in support of both fundamental and behavioral arguments.

Our findings also provide support that the behavior of LtA is state-dependent. The significance of risk factors depends on the subsample period, time-to-maturity, prevailing market conditions and the choice of determinants. The impacts are more pronounced for longer-term maturity bonds. The panel regressions explain between $18 \%$ to $24 \%$ in pre-crisis, $23 \%$ to $30 \%$ in liquidity crisis, $34 \%$ to $76 \%$ in credit crisis and $22 \%$ to $44 \%$ in after-crisis period. While Global Sentiment, Percieived Tail Event Risk and Funding constraints have negligible explanatory powers in the pre-crisis and after-crisis period, their impact becomes dramatic in the credit crisis phase. This suggests that arbitrageurs are affected by market sentiment during market turmoils, affecting their operations. Furthermore, funding costs (Secure Funding risk) affects the LtA via the spread that captures collateral values. However, these are mainly significant only when markets are dislocated. Otherwise, they do not have a major role in explaining the dynamics of LtA (during normal market periods). The impact of Macro-activity Risk is larger for longer maturity bonds, and their relevance becomes even bigger than the Global Funding factors. Heterogeneous beliefs and Equity Premium factors are also all significant, 
especially for the long-end of the term structure. Given that level of LtA increases with time-to-maturity, our findings give evidence that long term bonds are more sensitive to market shocks, and hence arbitrageurs tend to become more risk-averse. Friction (liquidity) factors are found to have lower impact than wasexpected during the liquidity crisis. This is almost counter-intuitive as one would have expected (traditional) liquidity factors to be most relevant during what we call the liquidity crisis. This result suggests that we may have to reconsider the way we proxy for liquidity risk. Finally, we find that the smoothing of LtA coincides with the US Government intervention via TARP and MBS purchases, though the real impact coincides with stress tests announcements. This suggests that the actions of US Government relieved the friction between financial institutions and investors, helping markets to stabilize over time, and decreasing the risk-aversion of market participants. This obviously bears welfare and policy implications left for further research.

Our findings also suggest that price discovery process tends to be regional in emerging markets: while usd-denominated bonds significantly lead their euro equivalents in Brazil and Mexico, the exact opposite relationship is observed in Turkey. As another important finding, the existence of currency-dependence suggests that employing usd as de facto currency to price all other foreign currency-denominated credit products is empirically incorrect for credit risk modeling. Curve estimations and credit pricing models concerning the risk premiums (across two currencies) should be built independently for each corresponding currency, even though the maturity and the issuer of both bonds are the same.

The generality of our examination is limited to the fact that so far we do not take into account the effect of country-specific fundamentals (i.e. usd exports vs. euro exports, usd reserves vs. euro reserves etc.), due to infrequency of data. Further research may be carried out on the role of country-specific market volatilities. Although the main focus here is on Emerging Markets sovereigns, the methodology and the intuition presented in this paper can be applied directly to multinational corporations, which issue debt in more than one currency. 


\section{References}

[1] Acharya, V. V., Pedersen, L. H., 2005. Asset Pricing with Liquidity Risk. Journal of Financial Economics 77, 375-410.

[2] Allen, F., Gale, D., 2004. Financial Intermediaries and Markets. Econometrica 72 (4), 1023-1061.

[3] Amihud, Y., Mendelson, H., 1986. Asset Pricing and the Bid-Ask Spread. Journal of Financial Economics 17, $223-249$.

[4] Baillie, R. T., Booth, G. G., Tse, Y., Zabotina, T., 2002. Price Discovery and Common Factor Models. Journal of Financial Markets 5, 309-321.

[5] Baker, M., Stein, J., 2004. Market Liquidity as a Sentiment Indicator. Journal of Financial Markets 7 (3), $271-299$.

[6] Baker, M., Wurgler, J., 2007. Investor Sentiment in the Stock Market. Journal of Economic Perspectives 21 (2), $129-151$.

[7] Bansal, R., Yaron, A., 2005. Risks for the Long Run: A Potential Resolution of Asset Pricing Puzzle. Journal of Finance 59 (4), 1481-1509.

[8] Basak, S. 2000. A Model of Dynamic Equilibrium Asset Pricing with Heterogeneous Beliefs and Extraneous Risk. Journal of Economic Dynamics and Control 24, 63-95.

[9] Beber, A., Breedon, F., Buraschi, A., 2010. Differences in Beliefs and Currency Risk Premiums. Journal of Financial Economics $98(3), 415-438$.

[10] Bernanke, B., Gertler, M., 1989. Agency Costs, Net Worth, and Business Fluctuations. American Economic Review 79 (1), $14-31$.

[11] Bernanke, B., 2009. The Crisis and the Policy Response. The Stamp Lecture of the London School of Economics, London, England.

[12] Bernard, V., Thomas, J., 1989. Post-Earnings-Announcement Drift: Delayed Price Response or Risk Premium? Journal of Accounting Research 27, 1-36.

[13] Blanco, R., Brennan, S., Marsh, I. W., 2005. An Empirical Analysis of the Dynamic Relation between Investment-Grade Bonds and Credit Default Swaps. Journal of Finance 60 (5), 2255-2281.

[14] Bloom, N., 2009. The Impact of Uncertainty Shocks. Econometrica 77 (3), 623-685.

[15] Bodurtha, J. N., Kim, D., Lee, C. M., 1995. Closed-end Country Funds and U.S. Market Sentiment. Review of Financial Studies $8(3), 879-918$.

[16] Boehmer, E., Megginson, W. L., 1990. Determinants of Secondary Market Prices for Developing Country Syndicated Loans. Journal of Finance 45 (5), 1517-1540.

[17] Breger, L., Stovel, D., 2005. Global Integration of Developed Credit Markets. The Journal of Portfolio Management 31 (3), 60-69.

[18] Brunnermeier, M. K., Pedersen, L. H., 2009. Market Liquidity and Funding Liquidity. Review of Financial Studies 22 (6), $2201-2238$

[19] Bulow, J., Rogoff, K., 1989. A Constant Recontracting Model of Sovereign Debt. Journal of Political Economy 97 (1), $155-178$.

[20] Buraschi, A., Jiltsov, A., 2006. Model Uncertainty and Option Markets in Heterogeneous Economies. Journal of Finance 61, 2841-2898.

[21] Buraschi, A., Menini, D., 2002. Liquidity Risk and Specialness. Journal of Financial Economics 64, $243-284$. 
[22] Buraschi, A., Trojani, F., Vedolin, A., 2009. Economic Uncertainty, Differences in Beliefs and Credit Markets. Journal of Political Economy, under submission.

[23] Caballero, R., Krishnamurthy, A., 2008. Collective Risk Management in a Flight to Quality Episode. Journal of Finance 63 (5), 2195-2236.

[24] Campbell, J. Y., Cochrane, J. H., 1999. By Force of Habit: A Consumption-Based Explanation of Aggregate Stock Market Behavior. Journal of Political Economy 107 (2), 205-251.

[25] Campbell, J. Y., Taksler, G. B., 2003. Equity Volatility and Corporate Bond Yields. Journal of Finance 58, $2321-2349$.

[26] Chen, L., Lesmond, D. A., Wei, J., 2007. Bond Liquidity Estimation and the Liquidity Effect in Yield Spreads. Journal of Finance $62,119-49$.

[27] Christensen, J. H., Lopez, J. A., Rudebusch G. D., 2009. Do Central Bank Liquidity Facilities Affect Interbank Lending Rates? Working Paper Series 2009-13, Federal Reserve Bank of San Francisco.

[28] Claessens, S., Pennacchi, G., 1996. Estimating the Likelihood of Mexican Default from the Market Prices of Brady Bonds. Journal of Financial and Quantitative Analysis 31 (1), 109-126.

[29] Collin-Dufresne, P., Goldstein, R. S., Martin, J. S., 2001. The Determinants of Credit Spread Changes. Journal of Finance 56 (6), 2177-2207.

[30] Cremers, M., Driessen, J., Maenhout, P., 2008. Explaining the Level of Credit Spreads: Option-Implied Jump Risk Premia in a Firm Value Model. Review of Financial Studies 21 (5), 2209-2242.

[31] Davydenko, S. A., Franks, J. R., 2008. Do Bankruptcy Codes Matter? A Study of Defaults in France, Germany, and the UK. Journal of Finance 63 (2), 565-608.

[32] Detemple, J. B., Murthy, S., 1994. Intertemporal Asset Pricing with Heterogeneous Beliefs. Journal of Economic Theory 62, 294-320.

[33] De Long, J. B., Shleifer, A., Summers, L. H., Waldmann, R. J., 1990. Noise Trader Risk in Financial Markets. Journal of Political Economy 98 (4), 703-738.

[34] Diebold, F. X., Li, C., 2006. Forecasting the Term Structure of Government Bond Yields. Journal of Econometrics 130, 337-364.

[35] Domowitz, I., Glen, J., Madhavan, A., 1998. Country and Currency Risk Premia in an Emerging Market. Journal of Financial and Quantitative Analysis 33 (2), 189-216.

[36] Dooley, H., Hutchison, M., 2009. Transmission of the U.S. Subprime Crisis to Emerging Markets: Evidence on the DecouplingRecoupling Hypothesis. Journal of International Money and Finance 28, 1331-1349.

[37] Driessen, J., 2005. Is Default Event Risk Priced in Corporate Bonds? Review of Financial Studies 18 (1), $165-195$.

[38] Duffee, G. R., 1999. Estimating the Price of Default Risk. Review of Financial Studies 12 (1), $197-226$.

[39] Duffie, D., Pedersen, L. H., Singleton, K. J, 2003. Modelling Sovereign Yield Spreads: A Case Study of Russian Debt. Journal of Finance 58 (1), 119-159.

[40] Eaton, J., Gersovitz, M., Stiglitz, J., 1986. The Pure Theory of Country Risk. European Economic Review 30, 481-513.

[41] Ehlers, P., Schönbucher, P., 2004. The Infuence of FX Risk on Credit Spreads. National Centre of Competence in Research Financial Valuation and Risk Management Working Paper Series No. 214. 
[42] Elton, E. J., Gruber, M. J., Agrawal, D., Mann, C., 2001. Explaining the Rate Spread on Corporate Bonds. Journal of Finance $56(1), 247-277$

[43] Epstein, L. G., Wang, T., 1994. Intertemporal Asset Pricing Under Knightian Uncertainty. Econometrica 62 (2), $283-322$.

[44] Epstein, L. G., Schneider, M., 2008. Ambiguity, Information Quality and Asset Pricing. Journal of Finance 63 (1), $197-228$.

[45] Ericsson, J., Renault, O., 2006. Liquidity and Credit Risk. Journal of Finance 61 (5), 2219-2250.

[46] Feder, G., Just, R., Ross, K., 1981. Projecting Debt Servicing Capacity of Developing Countries. Journal of Financial and Quantitative Analysis 16, 651-669.

[47] Feldhütter, P., Lando, D., 2008. Decomposing Swap Spreads. Journal of Financial Economics 88, 375-405.

[48] Fons, J. S., 1987. The Default Premium and Corporate Bond Experience. Journal of Finance 42 (1), $81-97$.

[49] Fontaine, J. S., Garcia, R., 2009. Bond Liquidity Premia. Bank of Canada Working Paper 2009-28.

[50] Fostel, A., Geanakoplos, J., 2008. Leverage Cycles and the Anxious Economy. American Economic Review 98 (4), $1211-1244$.

[51] Gabaix, X., Krishnamurthy, A., Vigneron, O., 2007. Limits of Arbitrage: Theory and Evidence from the Mortgage-Backed Securities Market. Journal of Finance 62 (2), 557-596.

[52] Geanakoplos, J., Polemarchakis, H., 1986. Existence, Regularity, and Constrained Suboptimality of Competitive Allocations When the Asset Market is Incomplete. Uncertainty, Information and Communication, Essays in Honor of Kenneth J. Arrow, ed. W Heller, R Starr, D Starrett, 3, 65-96. Cambridge UK, Cambridge University Press.

[53] Garleanu, N., Pedersen, L., 2007. Liquidity and Risk Management. American Economic Review 97 (2), $193-197$.

[54] Gilboa, I., Schmeidler, D., 1989. Maxmin Expected Utility with Non-unique Prior. Journal of Mathematical Economics 18 (2), 141-153.

[55] Goetzmann, W., Li, L., Rouwenhorst, G., 2005. Long-Term Global Market Correlations. Journal of Business 78, 1-38.

[56] Goldberg, L. S., Kennedy, C., Miu, J., 2010. Central Bank Dollar Swap Lines and Overseas Dollar Funding Costs. Federal Reserve Bank of New York Staff Papers No. 429

[57] Goldstein, M. A., Hotchkiss, E. S., Sirri, E. R., 2007. Transparency and Liquidity: A Controlled Experiment on Corporate Bonds. Review of Financial Studies 20 (2), 235-273.

[58] Gonzalo, J., Granger, C. W. J., 1995. Estimation of Common Long-Memory Components in Cointegrated Systems. Journal of Business and Economic Statistics 13, 27-35.

[59] Grinblatt, M., 2001. An Analytical Solution for Interest Rate Swap Spreads. International Review of Finance 2 (3), $113-149$.

[60] Gromb, D., Vayanos, D., 2002. Equilibrium and Welfare in Markets with Financially Constrained Arbitrageurs. Journal of Financial Economics 66, 361-407.

[61] Gromb, D., Vayanos, D., 2010. Limits of Arbitrage: The State of the Theory. The Paul Woolley Centre Working Paper Series No:9, Discussion Paper No:650.

[62] Grossman, S., Miller, M., 1988. Liquidity and Market Structure. Journal of Finance 43, 617-637. 
[63] Hart, O., Moore, J., 1995. An Analysis of the Role of Hard Claims in Constraining Management. American Economic Review 85, 567-585.

[64] Hasbrouck, J., 1995. One Security, Many Markets: Determining the Contributions to Price Discovery. Journal of Finance 50 (4), 1175-1199.

[65] Hausman, J. A., 1978. Specification Tests in Econometrics. Econometrica 46, 1251-1271.

[66] Houweling, P., Hoek, J., Kleibergen, F., 2001. The Joint Estimation of Term Structures and Credit Spreads. Journal of Empirical Finance 8, 297-323.

[67] Houweling, P., Vorst, T., 2005. Pricing Default Swaps: Empirical Evidence. Journal of International Money and Finance 24, 1200-1225.

[68] Hull, J., Predescu, M., White, A., 2004. The Relationship Between Credit Default Swap Spreads, Bond Yields, and Credit Rating Announcements. Journal of Banking and Finance 28, 2789-2811.

[69] International Monetary Fund, 2008. World Economic Outlook October 2008.

[70] Jankowitsch, R., Pichler, S., 2005. Currency Dependence of Corporate Credit Spreads. Journal of Risk 8, 1-24.

[71] Jegadeesh, N., Titman, S., 1993. Returns to Buying Winners and Selling Losers: Implications for Stock Market Efficiency. Journal of Finance 48, 65-91.

[72] Johansen, S., 1988. Statistical Analysis of Cointegrating Vectors. Journal of Economic Dynamics and Control 12, 231-254.

[73] Kacperczyk, M., Schnabl, P., 2010. When Safe Proved Risky: Commercial Paper During the Financial Crisis of 2007-2009. Journal of Economic Perspectives 24 (1), 29-50

[74] Kercheval, A., Goldberg, L., Breger, L., 2003. Modeling Credit Risk. Journal of Portfolio Management 29, 90-100.

[75] Knight, F., 1921. Risk, Uncertainty, and Profit. Boston, MA: Hart, Schaffner \& Marx; Houghton Mifflin Co.

[76] Krishnamurthy, A., 2010. How Debt Markets Have Malfunctioned in the Crisis. Journal of Economic Perspectives 24 (1), 3-28.

[77] Lamont, O., Thaler, R., 2003. Can the Market Add and Subtract? Mispricing in Tech Stock Carve-outs. Journal of Political Economy 111, 227-268.

[78] Landschoot, A. V., 2008. Determinants of Yield Spread Dynamics: Euro versus US Dollar Corporate Bonds. Journal of Banking and Finance 32, 2597-2605.

[79] Lehmann, B. N., 2002. Some Desiderata for the Measurement of Price Discovery Across Markets. Journal of Financial Markets $5,259-276$.

[80] Litterman, R., Scheinkman, J., 1991. Common Factors Affecting Bond Returns. Journal of Fixed Income 1, 54-61.

[81] Longstaff, F. A, 2010. The Subprime Credit Crisis and Contagion in Financial Markets. Journal of Financial Economics 97, 436-450.

[82] Longstaff, F. A, Neis, E., Mithal, S., 2005. Corporate Yield Spreads: Default Risk or Liquidity? New Evidence from the CreditDefault Swap Market. Journal of Finance 60, 2213-2254. 
[83] Longstaff, F. A, Pan, J., Pedersen, L. H., Singleton, K. J., 2008. How Sovereign is Sovereign Credit Risk? NBER Working Paper Series No: W13658.

[84] Ludvigson, S. C., Ng, S., 2009. Macro Factors in Bond Risk Premia. Review of Financial Studies 22 (12), 5027-5067.

[85] Maddala, G. S., 1971. The Use of Variance Components Models in Pooling Cross Section and Time Series Data. Econometrica 39 (2), 341-358

[86] Mahantia, S., Nashikkar, A., Subrahmanyam, M., Chacko, G., Mallik, G., 2008. Latent Liquidity: A New Measure of Liquidity, with an Application to Corporate Bonds. Journal of Financial Economics 88, 272-298.

[87] McAndrews, J., Sarkar, A., Wang, Z., 2008. Effects of the Term Auction Facility on the London Inter-Bank Offered Rate. Federal Reserve Bank of New York Staff Reports, No: 335.

[88] McCulloch, J. H., 1971. Measuring the Term Structure of Interest Rates. Journal of Business 44 (1), 19-31.

[89] McCulloch, J. H., 1975. The Tax-Adjusted Yield Curve. Journal of Finance 30 (3), 811-830.

[90] Merrill Lynch, 2000. Merrill Lynch Global Bond Indices-Rules of Construction and Calculation Methodology.

[91] Mitchell, M., Pedersen, L. H., Pulvino, T., 2007. Slow Moving Capital. American Economic Review 97 (2), 215-220.

[92] Mundlak, Y., 1978. On the Pooling of Time Series and Cross Section Data. Econometrica 46, 69-85.

[93] Rice, J., Rosenblatt, M., 1983. Smoothing Splines: Regression, Derivatives and Deconvolution. Annals of Statistics 11 (1), 141 156 .

[94] Nelson, C. R., Siegel, A. F., 1987. Parsimonious Modeling of Yield Curves. Journal of Business 60, 473-489.

[95] Nerlove, M., Balestra, P., 1966. Pooling Cross Section and Time Series Data in the Estimation of a Dynamic Model: The Demand for Natural Gas. Econometrica 34 (3), 585-612

[96] Nickell, S., 1981. Biases in Dynamic Models with Fixed Effects. Econometrica 49 (6), 1417-1426.

[97] Nychka, D., 1995. Splines as Local Smoothers. Annals of Statistics 23 (4), 1175-1197.

[98] Ofek, E., Richardson, M., Whitelaw, R., 2004. Limited Arbitrage and Short Sales Restrictions: Evidence From the Options Markets. Journal of Financial Economics 74, 305-342.

[99] Shea, G. S., 1985. Interest Rate Term Structure Estimation with Exponential Splines: A Note. Journal of Finance 40 (1), 319-325.

[100] Pan, J., Singleton, K. J., 2008. Default and Recovery Implicit in the Term Structure of Sovereign CDS Spreads. Journal of Finance $63(5), 2345-2384$

[101] Roll, R., 1988. The International Crash of October 1987. Financial Analysts Journal 44 (5), 19-35.

[102] Rosenthal, L., Young, C., 1990. The Seemingly Anomalous Price Behavior of Royal Dutch/Shell and Unilever N.V./PLC. Journal of Financial Economics 26 (1), 123-141.

[103] Saini, K. G., Bates, P. S., 1984. A survey of the Quantitative Approaches to Country Risk Analysis. Journal of Banking and Finance 8, 341-356

[104] Sarkar, A., Shrader, J., 2010. Financial Amplification Mechanisms and the Federal Reserve's Supply of Liquidity During the Crisis. Federal Reserve Bank of New York Staff Reports No. 431. 
[105] Shleifer, A., 2000. Inefficient Markets. Oxford University Press, New York.

[106] Shleifer, A. and R. Vishny (1997). The Limits of Arbitrage. Journal of Finance 52, 35-55.

[107] Svensson, L. E. O., 1994. Estimating and Interpreting Forward Interest Rates: Sweden 1992-4. International Monetary Fund Working Paper 114.

[108] Taylor, J. B., Williams, J. C., 2009. A Black Swan in the Money Market. American Economic Journal: Macroeconomics, American Economic Association, 1 (1), 58-83.

[109] Tuckman, B., Vila, J. L., 1992. Arbitrage With Holding Costs: A Utility-Based Approach. Journal of Finance 47, $1283-1302$.

[110] Vasicek, O. A., Fong, H. G., 1982. Term Structure Modeling Using Exponential Splines. Journal of Finance 37 (2), 339-348.

[111] Vayanos, D., Vila, J. L., 2009. A Preferred-Habitat Model of the Term Structure of Interest Rates. The Paul Woolley Centre Working Paper Series No:6, Discussion Paper No:641. 
Table 1: This table gives the total number of usd- and euro-denominated Eurobonds issued by Brazil, Mexico and Turkey as of July 2005. These numbers are subject to change throughout the sample data period, since several bonds have matured and new bonds have been issued during $2005-2010$.

\begin{tabular}{|c|c|c|c|c|}
\hline EUR & 1-3 Years & 3-6 Years & 6-9 Years & 9-15 Years \\
\hline Turkey & 2 & 2 & 1 & 5 \\
\hline Brazil & 2 & 1 & 2 & 5 \\
\hline Mexico & 1 & 2 & 2 & 5 \\
\hline Total & 5 & 5 & 5 & 15 \\
\hline USD & 1-3 Years & 3-6 Years & 6-9 Years & 9-15 Years \\
\hline Turkey & 4 & 3 & 3 & 13 \\
\hline Brazil & 5 & 4 & 3 & 10 \\
\hline Mexico & 3 & 4 & 1 & 3 \\
\hline Total & 12 & 11 & 7 & 26 \\
\hline
\end{tabular}


Table 2: This table presents the average usd and euro credit risk premiums (in percentages) by country and maturity buckets. Standard deviations (in percentages) are given immediately below average values. The entire data set is divided into four sub-samples: pre-crisis, liquidity crisis, credit crisis and after-crisis periods.

\begin{tabular}{|c|c|c|c|c|c|c|c|}
\hline \multirow[t]{2}{*}{ Year } & \multirow[t]{2}{*}{ Maturity } & \multirow{2}{*}{$\begin{array}{l}\text { USD } \\
\text { Turkey }\end{array}$} & \multicolumn{2}{|c|}{ Risk Premiums } & \multicolumn{3}{|c|}{ EUR Risk Premiums } \\
\hline & & & Brazil & Mexico & Turkey & Brazil & Mexico \\
\hline \multirow{8}{*}{$\begin{array}{c}\text { Pre-Crisis Period } \\
\text { (1 July 2005-8 August 2007) }\end{array}$} & 1-3 Years & 0.5811 & 0.4199 & 0.0697 & 0.4662 & 0.4191 & 0.1018 \\
\hline & & 0.2812 & 0.3218 & 0.0706 & 0.2709 & 0.4128 & 0.0672 \\
\hline & 3-6 Years & 1.1709 & 0.9319 & 0.2213 & 1.0580 & 1.0737 & 0.3068 \\
\hline & & 0.3500 & 0.6574 & 0.1325 & 0.3426 & 0.8294 & 0.1663 \\
\hline & 6-9 Years & 1.4146 & 1.1830 & 0.3294 & 1.3405 & 1.4033 & 0.4485 \\
\hline & & 0.3559 & 0.7932 & 0.1736 & 0.3309 & 0.9331 & 0.2178 \\
\hline & 9-15 Years & 1.6575 & 1.4603 & 0.4851 & 1.6484 & 1.7854 & 0.6541 \\
\hline & & 0.3670 & 0.9168 & 0.2256 & 0.3074 & 0.9973 & 0.2680 \\
\hline \multirow{8}{*}{$\begin{array}{l}\text { Liquidity Crisis Period } \\
\text { (9 August 2007-29 August 2008) }\end{array}$} & 1-3 Years & 1.1300 & 0.5012 & 0.4512 & 0.6833 & 0.5198 & 0.2684 \\
\hline & & 0.3963 & 0.2590 & 0.2565 & 0.2921 & 0.2625 & 0.1727 \\
\hline & 3-6 Years & 1.8212 & 0.8832 & 0.6147 & 1.3975 & 1.0630 & 0.5460 \\
\hline & & 0.4860 & 0.3445 & 0.2710 & 0.3635 & 0.3565 & 0.2994 \\
\hline & 6-9 Years & 1.9893 & 1.0079 & 0.6575 & 1.6491 & 1.2707 & 0.6735 \\
\hline & & 0.4965 & 0.3520 & 0.2653 & 0.3634 & 0.3926 & 0.3398 \\
\hline & 9-15 Years & 2.1095 & 1.1172 & 0.6914 & 1.8719 & 1.4675 & 0.8181 \\
\hline & & 0.4992 & 0.3531 & 0.2521 & 0.3677 & 0.4473 & 0.3701 \\
\hline \multirow{8}{*}{$\begin{array}{c}\text { Credit Crisis Period } \\
\text { (1 September 2008 - 31 March 2009) }\end{array}$} & 1-3 Years & 4.5206 & 2.0587 & 1.5648 & 3.3900 & 2.9074 & 1.9416 \\
\hline & & 1.8348 & 0.8687 & 0.5546 & 1.4920 & 1.4591 & 1.2516 \\
\hline & 3-6 Years & 4.9910 & 3.1026 & 2.7387 & 3.8365 & 3.6803 & 2.8097 \\
\hline & & 1.5264 & 0.9783 & 0.8830 & 1.4184 & 1.2589 & 0.9507 \\
\hline & 6-9 Years & 5.0858 & 3.3758 & 3.0671 & 3.9342 & 3.8629 & 3.1226 \\
\hline & & 1.4716 & 1.0053 & 0.9898 & 1.3726 & 1.1997 & 0.9514 \\
\hline & 9-15 Years & 5.1565 & 3.5855 & 3.3174 & 4.0129 & 4.0006 & 3.4052 \\
\hline & & 1.4358 & 1.0330 & 1.0891 & 1.3325 & 1.1522 & 1.0002 \\
\hline \multirow{8}{*}{$\begin{array}{l}\text { After-Crisis Period } \\
\text { (1 April 2009-30 April 2010) }\end{array}$} & 1-3 Years & 1.9107 & 0.7307 & 0.6364 & 1.5069 & 0.7447 & 0.6667 \\
\hline & & 0.6992 & 0.3680 & 0.2929 & 0.7318 & 0.5135 & 0.3070 \\
\hline & 3-6 Years & 2.4538 & 1.4017 & 1.3229 & 1.8178 & 1.4391 & 1.3707 \\
\hline & & 0.7666 & 0.5837 & 0.5182 & 0.5863 & 0.6513 & 0.5463 \\
\hline & 6-9 Years & 2.5745 & 1.6352 & 1.5776 & 1.9098 & 1.7552 & 1.7155 \\
\hline & & 0.7776 & 0.6287 & 0.5757 & 0.5380 & 0.6123 & 0.6325 \\
\hline & 9-15 Years & 2.6641 & 1.8381 & 1.8110 & 1.9872 & 2.1247 & 2.1160 \\
\hline & & 0.7829 & 0.6505 & 0.6196 & 0.5002 & 0.5415 & 0.7182 \\
\hline
\end{tabular}


Table 3: This table presents the average absolute LtA values (in percentages) by country and maturity buckets, derived from the no-arbitrage equilibrium function. Standard deviations (in percentages) are given immediately below the average values. The entire data set is divided into four sub-samples: pre-crisis, liquidity crisis, credit crisis and after-crisis periods.

\begin{tabular}{|c|c|c|c|c|}
\hline \multirow[t]{2}{*}{ Year } & \multirow[t]{2}{*}{ Maturity } & \multicolumn{3}{|c|}{ Emerging Markets } \\
\hline & & Turkey & Brazil & Mexico \\
\hline \multirow[t]{7}{*}{$\begin{array}{l}\text { Pre-Crisis Period } \\
\text { (1 July 2005-8 August 2007) }\end{array}$} & 1-3 Years & $\begin{array}{l}0.0628 \\
0.0509\end{array}$ & $\begin{array}{l}0.0634 \\
0.0750\end{array}$ & $\begin{array}{l}0.0305 \\
0.0274\end{array}$ \\
\hline & 3-6 Years & 0.0643 & 0.0776 & 0.0440 \\
\hline & & 0.0551 & 0.0803 & 0.0362 \\
\hline & 6-9 Years & 0.0649 & 0.0827 & 0.0498 \\
\hline & & 0.0556 & 0.0748 & 0.0422 \\
\hline & 9-15 Years & 0.0617 & 0.0711 & 0.0518 \\
\hline & & 0.0608 & 0.0655 & 0.0468 \\
\hline \multirow{8}{*}{$\begin{array}{l}\text { Liquidity Crisis Period } \\
\text { (9 August 2007-29 August 2008) }\end{array}$} & 1-3 Years & 0.1577 & 0.1234 & 0.1111 \\
\hline & & 0.1692 & 0.1062 & 0.0976 \\
\hline & 3-6 Years & 0.1545 & 0.1510 & 0.1281 \\
\hline & & 0.1330 & 0.1413 & 0.1006 \\
\hline & 6-9 Years & 0.1383 & 0.1420 & 0.1263 \\
\hline & & 0.1291 & 0.1373 & 0.0990 \\
\hline & 9-15 Years & 0.1341 & 0.1349 & 0.1130 \\
\hline & & 0.1294 & 0.1291 & 0.0958 \\
\hline \multirow{8}{*}{$\begin{array}{l}\text { Credit Crisis Period } \\
\text { (1 September 2008 - 31 March 2009) }\end{array}$} & 1-3 Years & 0.8108 & 0.5588 & 0.7426 \\
\hline & & 0.7259 & 0.4764 & 0.8727 \\
\hline & 3-6 Years & 0.8101 & 0.4995 & 0.6328 \\
\hline & & 0.7139 & 0.4036 & 0.6788 \\
\hline & 6-9 Years & 0.8527 & 0.5444 & 0.6984 \\
\hline & & 0.7908 & 0.5495 & 0.8604 \\
\hline & 9-15 Years & 0.8982 & 0.5800 & 0.7586 \\
\hline & & 0.8632 & 0.6867 & 1.0678 \\
\hline \multirow{8}{*}{$\begin{array}{l}\text { After-Crisis Period } \\
(1 \text { April } 2009-30 \text { April 2010) }\end{array}$} & 1-3 Years & 0.2103 & 0.1213 & 0.1321 \\
\hline & & 0.2301 & 0.1094 & 0.1258 \\
\hline & 3-6 Years & 0.1623 & 0.1439 & 0.1788 \\
\hline & & 0.1827 & 0.1023 & 0.1335 \\
\hline & 6-9 Years & 0.1645 & 0.1628 & 0.1745 \\
\hline & & 0.1743 & 0.1163 & 0.1325 \\
\hline & 9-15 Years & 0.1770 & 0.2213 & 0.1659 \\
\hline & & 0.1802 & 0.1702 & 0.1493 \\
\hline
\end{tabular}


Table 4: This table presents the comparative analysis between the absolute LtA values and the bid-ask spread yields of bonds (across two currencies) by country and time-to-maturity in given sample period. The bid-ask spread is estimated as the difference between the ask and the bid price divided by the mid price of a bond. $E$ [absolute $(L t A)-B i d A s k]$ is denoted at the top, and $\sigma_{L t a}-\sigma_{B i d A s k}$ is denoted immediately below. Figures are presented as percentage values. The entire data set is divided into four sub-samples: pre-crisis, liquidity crisis, credit crisis and after-crisis periods.

\begin{tabular}{|c|c|c|c|c|c|c|c|}
\hline \multirow[t]{2}{*}{ Year } & \multirow[t]{2}{*}{ Maturity } & \multirow{2}{*}{\multicolumn{3}{|c|}{ ABSLtA vs. Bid/Ask (US) }} & \multicolumn{3}{|c|}{ ABSLtA vs. Bid/Ask (EUR) } \\
\hline & & & & & Turkey & Brazil & Mexico \\
\hline \multirow{8}{*}{$\begin{array}{l}\text { Pre-Crisis Period } \\
\text { (1 July 2005-8 August 2007) }\end{array}$} & 1-3 Years & 0.0257 & 0.0091 & -0.0262 & -0.0008 & 0.0091 & -0.0016 \\
\hline & & 0.0497 & 0.0720 & 0.0316 & 0.0499 & 0.0741 & 0.0285 \\
\hline & 3-6 Years & -0.0044 & 0.0223 & -0.0318 & -0.0212 & 0.0167 & -0.0596 \\
\hline & & 0.0534 & 0.0815 & 0.0462 & 0.0540 & 0.0821 & 0.0414 \\
\hline & 6-9 Years & -0.0146 & 0.0294 & -0.0432 & -0.0213 & -0.0134 & -0.0623 \\
\hline & & 0.0544 & 0.0770 & 0.0490 & 0.0594 & 0.0866 & 0.0472 \\
\hline & 9-15 Years & -0.0253 & 0.0144 & -0.0502 & -0.0302 & 0.0008 & -0.0630 \\
\hline & & 0.0578 & 0.0661 & 0.0509 & 0.0682 & 0.0672 & 0.0481 \\
\hline \multirow{8}{*}{$\begin{array}{l}\text { Liquidity Crisis Period } \\
\text { (9 August 2007-29 August 2008) }\end{array}$} & 1-3 Years & 0.1198 & 0.0411 & 0.0574 & 0.0868 & 0.0726 & 0.0827 \\
\hline & & 0.1707 & 0.1086 & 0.0968 & 0.1697 & 0.1062 & 0.0970 \\
\hline & 3-6 Years & 0.0827 & 0.0533 & 0.0402 & 0.0668 & 0.0880 & 0.0316 \\
\hline & & 0.1348 & 0.1438 & 0.1175 & 0.1284 & 0.1469 & 0.0989 \\
\hline & 6-9 Years & 0.0486 & 0.0743 & 0.0377 & 0.0457 & 0.0593 & 0.0409 \\
\hline & & 0.1253 & 0.1411 & 0.1161 & 0.1303 & 0.1384 & 0.1109 \\
\hline & 9-15 Years & 0.0475 & 0.0592 & 0.0193 & 0.0386 & 0.0781 & -0.0033 \\
\hline & & 0.1293 & 0.1298 & 0.1007 & 0.1273 & 0.1303 & 0.1007 \\
\hline \multirow{8}{*}{$\begin{array}{l}\text { Credit Crisis Period } \\
\text { (1 September 2008 - 31 March 2009) }\end{array}$} & 1-3 Years & 0.7706 & 0.4861 & 0.6769 & 0.7383 & 0.4988 & 0.7078 \\
\hline & & 0.7271 & 0.4796 & 0.8696 & 0.7280 & 0.4717 & 0.8710 \\
\hline & 3-6 Years & 0.7278 & 0.3971 & 0.5698 & 0.6893 & 0.3987 & 0.5383 \\
\hline & & 0.7166 & 0.3992 & 0.6940 & 0.7072 & 0.3940 & 0.6891 \\
\hline & 6-9 Years & 0.7424 & 0.4987 & 0.5782 & 0.7686 & 0.4559 & 0.6218 \\
\hline & & 0.7857 & 0.5478 & 0.8567 & 0.7872 & 0.5491 & 0.8474 \\
\hline & 9-15 Years & 0.7834 & 0.4925 & 0.6123 & 0.8016 & 0.5206 & 0.6762 \\
\hline & & 0.8603 & 0.6811 & 1.0487 & 0.8651 & 0.6862 & 1.0588 \\
\hline \multirow{8}{*}{$\begin{array}{l}\text { After-Crisis Period } \\
\text { (1 April 2009-30 April 2010) }\end{array}$} & 1-3 Years & 0.1702 & 0.0529 & 0.0651 & 0.1289 & 0.0555 & 0.0967 \\
\hline & & 0.2302 & 0.1077 & 0.1295 & 0.2316 & 0.1203 & 0.1275 \\
\hline & 3-6 Years & 0.0794 & 0.0490 & 0.1356 & 0.0527 & 0.0428 & 0.0864 \\
\hline & & 0.1826 & 0.1076 & 0.1359 & 0.1798 & 0.1019 & 0.1408 \\
\hline & 6-9 Years & 0.0613 & 0.0991 & 0.0723 & 0.0683 & 0.0731 & 0.0787 \\
\hline & & 0.1764 & 0.1370 & 0.1197 & 0.1758 & 0.1134 & 0.1404 \\
\hline & 9-15 Years & 0.0748 & 0.1206 & 0.0470 & 0.0854 & 0.1611 & 0.0635 \\
\hline & & 0.1801 & 0.1744 & 0.1433 & 0.1853 & 0.1697 & 0.1511 \\
\hline
\end{tabular}



Table 5: For each bond of country $j$ having weekly quotes for at least four maturity periods $m$, the dependent variable LtA fim $_{j}$ over the time period 1 July 2005 to 30 April 2010 is estimated with the following

$\Delta A B S L t A_{j m t}=a_{j m t}+B_{1 m} \Delta(\mathrm{DiB})_{t}+B_{2 m} \Delta(\mathrm{FG}-\mathrm{Liq})_{t}+B_{3 m} \Delta(\mathrm{LN}-\mathrm{Macro})_{t}+B_{4 m} \Delta(\mathrm{USD} \text { Slope })_{t}+$

$B_{5 m} \Delta(\mathrm{VIX})_{t}+B_{6 m} \Delta(\mathrm{VIX}) * \Delta(\mathrm{VIX})_{t}+B_{7 m} \Delta(\text { Sentiment })_{t}+B_{8} \Delta(\mathrm{EM}-\mathrm{CDSI})_{t}+$

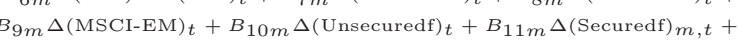

$B_{12 m} \Delta$ (DIVY) $_{m, t}+B_{13 m} \Delta(\mathrm{CP})_{j, m, t}+B_{14 m} \Delta\left(\right.$ ABSLtA $_{j, m, t-1}+B_{15 j m} \Delta\left(\mathrm{BIDASK}_{j, m, t}\right.$

The panel includes the absolute LtA series (i.e. ABSLtA of three countries: Turkey, Brazil and Mexico), and the first ABSLtA lags. Variables are made stationary by taking first-differences. All independent variables, factor in US, denoted as Securedf, is maturity-specific. Other variables are neither bond- nor maturity-specific. The unsecured funding factor in US is denoted as $U n$ securedf. The EM - CDSI is the Markit CDX

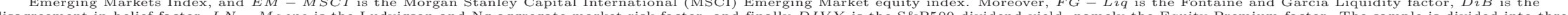
periods: pre-crisis, crisis and after-crisis periods. Quotes are discarded whenever a bond has less than 6 months to maturity. Quotes are included whenever a bond has more than 6 months since issuance. Average
parameter estimates are reported below, and the associated t-statistics for each parameter are displayed immediately beneath. For each regression the coefficient of determinations are included. ( ${ }^{*}$ ) shows $\% 95$ and

\begin{tabular}{|c|c|c|c|c|c|c|c|c|c|c|c|c|}
\hline \multirow[t]{3}{*}{ Coefficients } & \multicolumn{4}{|c|}{ Pre-Crisis Period } & \multicolumn{4}{|c|}{ Crisis Period } & \multicolumn{4}{|c|}{ After-Crisis Period } \\
\hline & & (1 July 2005 & 8 August 2007) & & & (9 August 2007 & 31 March 200 & & & (1 April 200 & 30 April 2010 & \\
\hline & 1-3 Years & 3-6 Years & 6-9 Years & 9-15 Years & 1-3 Years & 3-6 Years & 6-9 Years & 9-15 Years & 1-3 Years & 3-6 Years & 6-9 Years & 9-15 Years \\
\hline DiB & $\begin{array}{r}-0.8281 \\
-3^{*}\end{array}$ & $\begin{array}{r}-0.4642 \\
-2^{* *}\end{array}$ & $\begin{array}{l}-0.3930 \\
-1.2922\end{array}$ & $\begin{array}{l}-0.0039 \\
-0.0123\end{array}$ & $\begin{array}{r}2.9970 \\
3^{*}\end{array}$ & $\begin{array}{l}-0.1231 \\
-0.1541\end{array}$ & $\begin{array}{l}0.4859 \\
0.5012\end{array}$ & $\begin{array}{l}-0.3350 \\
-0.3131\end{array}$ & $\begin{array}{l}-0.3639 \\
-0.3660\end{array}$ & $\begin{array}{r}-0.2130 \\
-0.2808\end{array}$ & $\begin{array}{l}-0.1701 \\
-0.2262\end{array}$ & $\begin{array}{l}0.0529 \\
0.0562\end{array}$ \\
\hline FG-Liq & $\begin{array}{l}-0.0142 \\
-0.1258\end{array}$ & $\begin{array}{l}-0.0092 \\
-0.0783\end{array}$ & $\begin{array}{l}0.0551 \\
0.4353\end{array}$ & $\begin{array}{l}0.1998 \\
1.5233\end{array}$ & $\begin{array}{l}1.1748 \\
0.9768\end{array}$ & $\begin{array}{l}-1.8948 \\
-2^{* * *}\end{array}$ & $\begin{array}{l}-1.7497 \\
-1.4865\end{array}$ & $\begin{array}{l}-2.4317 \\
-2^{* *}\end{array}$ & $\begin{array}{l}1.7629 \\
1.6334\end{array}$ & $\begin{array}{r}1.4867 \\
2^{* *}\end{array}$ & $\begin{array}{l}0.8233 \\
0.9937\end{array}$ & $\begin{array}{l}-0.0199 \\
-0.0187\end{array}$ \\
\hline LG-Macro & $\begin{array}{l}-0.0125 \\
-1.2621\end{array}$ & $\begin{array}{l}0.0164 \\
1.6344\end{array}$ & $\begin{array}{l}0.0077 \\
0.7073\end{array}$ & $\begin{array}{l}-0.0150 \\
-1.3359\end{array}$ & $\begin{array}{l}-0.0502 \\
-0.5821\end{array}$ & $\begin{array}{l}-0.0623 \\
-0.8837\end{array}$ & $\begin{array}{r}-0.1617 \\
-2^{* *}\end{array}$ & $\begin{array}{r}-0.3006 \\
-3^{*}\end{array}$ & $\begin{array}{l}-0.0221 \\
-0.4571\end{array}$ & $\begin{array}{l}0.0626 \\
1.5090\end{array}$ & $\begin{array}{l}0.0320 \\
0.8835\end{array}$ & $\begin{array}{l}0.0041 \\
0.0888\end{array}$ \\
\hline USD Slope & $\begin{array}{l}0.0279 \\
0.5712\end{array}$ & $\begin{array}{l}-0.0499 \\
-0.9585\end{array}$ & $\begin{array}{l}-0.0477 \\
-0.8670\end{array}$ & $\begin{array}{l}0.0504 \\
0.8843\end{array}$ & $\begin{array}{l}0.1335 \\
0.7731\end{array}$ & $\begin{array}{l}-0.0511 \\
-0.3633\end{array}$ & $\begin{array}{l}0.1722 \\
0.9868\end{array}$ & $\begin{array}{l}-0.1286 \\
-0.6799\end{array}$ & $\begin{array}{r}-0.0938 \\
-0.6196\end{array}$ & $\begin{array}{l}0.0018 \\
0.0153\end{array}$ & $\begin{array}{l}0.1587 \\
1.3864\end{array}$ & $\begin{array}{l}0.2159 \\
1.5405\end{array}$ \\
\hline VIX & $\begin{array}{l}0.0009 \\
0.3200\end{array}$ & $\begin{array}{l}0.0014 \\
0.4983\end{array}$ & $\begin{array}{l}0.0002 \\
0.0594\end{array}$ & $\begin{array}{l}-0.0018 \\
-0.5739\end{array}$ & $\begin{array}{l}0.0090 \\
0.8983\end{array}$ & $\begin{array}{c}-0.0187 \\
-2^{* *}\end{array}$ & $\begin{array}{l}-0.0144 \\
-1.4390\end{array}$ & $\begin{array}{r}-0.0278 \\
-3^{*}\end{array}$ & $\begin{array}{l}-0.0132 \\
-1.6086\end{array}$ & $\begin{array}{l}-0.0057 \\
-0.8981\end{array}$ & $\begin{array}{l}-0.0035 \\
-0.5599\end{array}$ & $\begin{array}{l}-0.0093 \\
-1.1551\end{array}$ \\
\hline $\operatorname{vix}^{2}$ & $\begin{array}{l}-0.0004 \\
-0.6835\end{array}$ & $\begin{array}{r}-0.0006 \\
-1.0164\end{array}$ & $\begin{array}{l}-0.0001 \\
-0.2491\end{array}$ & $\begin{array}{l}-0.0006 \\
-1.0662\end{array}$ & $\begin{array}{l}0.0000 \\
0.1289\end{array}$ & $\begin{array}{r}0.0023 \\
7^{*}\end{array}$ & $\begin{array}{r}0.0030 \\
8^{*}\end{array}$ & $\begin{array}{r}0.0034 \\
8^{*}\end{array}$ & $\begin{array}{l}0.0010 \\
0.8015\end{array}$ & $\begin{array}{l}0.0015 \\
1.6104\end{array}$ & $\begin{array}{c}0.0016 \\
2^{* *}\end{array}$ & $\begin{array}{l}0.0014 \\
1.2595\end{array}$ \\
\hline Sentiment & $\begin{array}{r}-0.0115 \\
-2^{*}\end{array}$ & $\begin{array}{l}0.0021 \\
0.3744\end{array}$ & $\begin{array}{l}-0.0045 \\
-0.7135\end{array}$ & $\begin{array}{l}-0.0082 \\
-1.3181\end{array}$ & $\begin{array}{l}0.0092 \\
0.2931\end{array}$ & $\begin{array}{r}0.1154 \\
5^{*}\end{array}$ & $\begin{array}{r}0.1362 \\
4^{*}\end{array}$ & $\begin{array}{r}0.1428 \\
4^{*}\end{array}$ & $\begin{array}{r}-0.0041 \\
-0.1794\end{array}$ & $\begin{array}{l}0.0076 \\
0.4335\end{array}$ & $\begin{array}{l}-0.0053 \\
-0.3011\end{array}$ & $\begin{array}{l}-0.0269 \\
-1.2524\end{array}$ \\
\hline EM-CDSI & $\begin{array}{l}0.0012 \\
1.6003\end{array}$ & $\begin{array}{l}-0.0002 \\
-0.2783\end{array}$ & $\begin{array}{l}-0.0012 \\
-1.3523\end{array}$ & $\begin{array}{l}-0.0001 \\
-0.0818\end{array}$ & $\begin{array}{r}0.0373 \\
2^{* *}\end{array}$ & $\begin{array}{l}0.0262 \\
1.4270\end{array}$ & $\begin{array}{l}-0.0093 \\
-0.4156\end{array}$ & $\begin{array}{l}-0.0234 \\
-0.9554\end{array}$ & $\begin{array}{r}0.0282 \\
2^{*}\end{array}$ & $\begin{array}{l}-0.0087 \\
-0.9223\end{array}$ & $\begin{array}{r}-0.0188 \\
-2^{*}\end{array}$ & $\begin{array}{r}-0.0379 \\
-3^{*}\end{array}$ \\
\hline MSCI-EM & $\begin{array}{r}0.0000 \\
-1.2045\end{array}$ & $\begin{array}{r}0.0000 \\
-0.7517\end{array}$ & $\begin{array}{r}0.0000 \\
-0.7623\end{array}$ & $\begin{array}{r}0.0000 \\
-1.4901\end{array}$ & $\begin{array}{r}0.0000 \\
-0.6442\end{array}$ & $\begin{array}{r}0.0000 \\
-1.3300\end{array}$ & $\begin{array}{r}0.0000 \\
-0.3524\end{array}$ & $\begin{array}{r}0.0000 \\
-0.8626\end{array}$ & $\begin{array}{r}0.0000 \\
-1.1526\end{array}$ & $\begin{array}{l}0.0000 \\
1.3358\end{array}$ & $\begin{array}{l}0.0000 \\
1.3713\end{array}$ & $\begin{array}{l}0.0000 \\
0.3585\end{array}$ \\
\hline Unsecured US & $\begin{array}{l}0.0473 \\
0.2276\end{array}$ & $\begin{array}{l}0.1492 \\
0.6818\end{array}$ & $\begin{array}{l}0.1190 \\
0.5131\end{array}$ & $\begin{array}{l}-0.0866 \\
-0.3548\end{array}$ & $\begin{array}{l}0.1879 \\
0.8746\end{array}$ & $\begin{array}{l}0.1455 \\
0.8403\end{array}$ & $\begin{array}{r}0.3578 \\
2^{* *}\end{array}$ & $\begin{array}{l}-0.0063 \\
-0.0272\end{array}$ & $\begin{array}{l}-0.4017 \\
-0.6997\end{array}$ & $\begin{array}{r}-0.3205 \\
-0.7356\end{array}$ & $\begin{array}{l}-0.2401 \\
-0.5329\end{array}$ & $\begin{array}{r}-0.5493 \\
-1.0177\end{array}$ \\
\hline Secured US & $\begin{array}{r}0.4282 \\
3^{*}\end{array}$ & $\begin{array}{l}0.2251 \\
1.2944\end{array}$ & $\begin{array}{l}-0.2609 \\
-2 * *\end{array}$ & $\begin{array}{l}0.2220 \\
1.2195\end{array}$ & -0.6048 & $\begin{array}{r}0.9756 \\
5^{*}\end{array}$ & $\begin{array}{c}1.0126 \\
5^{*}\end{array}$ & $\begin{array}{r}1.8719 \\
7^{*}\end{array}$ & $\begin{aligned} 0.7043 \\
2^{* *}\end{aligned}$ & $\begin{array}{r}-0.3051 \\
-1.2732\end{array}$ & $\begin{array}{l}0.0120 \\
0.0887\end{array}$ & $\begin{array}{l}0.0899 \\
0.3366\end{array}$ \\
\hline DIVY & $\begin{array}{r}0.3230 \\
2^{* *}\end{array}$ & $\begin{array}{r}0.3860 \\
2^{*}\end{array}$ & $\begin{array}{r}0.5080 \\
3^{*}\end{array}$ & $\begin{array}{l}0.1544 \\
0.7370\end{array}$ & $\begin{array}{l}0.3928 \\
1.0506\end{array}$ & $\begin{array}{l}-0.2449 \\
-0.8200\end{array}$ & $\begin{array}{l}-0.4779 \\
-1.3533\end{array}$ & $\begin{array}{r}-1.2287 \\
-3^{*}\end{array}$ & $\begin{array}{r}-0.0911 \\
-0.2360\end{array}$ & $\begin{array}{l}0.0264 \\
0.0869\end{array}$ & $\begin{array}{l}-0.3608 \\
-1.2073\end{array}$ & $\begin{array}{r}-0.7663 \\
-2^{*}\end{array}$ \\
\hline $\mathrm{CP}$ & $\begin{array}{l}0.0000 \\
0.0532\end{array}$ & $\begin{array}{r}0.0000 \\
-0.0774\end{array}$ & $\begin{array}{l}-0.0003 \\
-0.8271\end{array}$ & $\begin{array}{l}-0.0003 \\
-0.9473\end{array}$ & $\begin{array}{r}-0.0020 \\
-2^{* *}\end{array}$ & $\begin{array}{l}0.0003 \\
0.3075\end{array}$ & $\begin{array}{r}0.0005 \\
-0.7520\end{array}$ & $\begin{array}{l}0.0010 \\
0.9152\end{array}$ & $\begin{array}{l}0.0004 \\
0.8874\end{array}$ & $\begin{array}{l}0.0003 \\
0.8460\end{array}$ & $\begin{array}{l}0.0001 \\
0.1511\end{array}$ & $\begin{array}{l}-0.0003 \\
-0.6451\end{array}$ \\
\hline $\operatorname{ABSMLTA}(-1)$ & $\begin{array}{r}-0.3127 \\
-6^{*}\end{array}$ & $\begin{array}{r}-0.3517 \\
-7^{*}\end{array}$ & $\begin{array}{r}-0.3950 \\
-7^{*}\end{array}$ & $\begin{array}{r}-0.3749 \\
-7^{*}\end{array}$ & $\begin{array}{r}-0.4278 \\
-7^{*}\end{array}$ & $\begin{array}{c}-0.5470 \\
-11^{*}\end{array}$ & $\begin{array}{r}-0.5310 \\
-10^{*}\end{array}$ & $\begin{array}{r}-0.4459 \\
-8^{*}\end{array}$ & $\begin{array}{r}-0.4036 \\
-5^{*}\end{array}$ & $\begin{array}{r}-0.5093 \\
-7^{*}\end{array}$ & $\begin{array}{r}-0.5495 \\
-9^{*}\end{array}$ & $\begin{array}{r}-0.5119 \\
-8^{*}\end{array}$ \\
\hline $\begin{array}{r}\text { BIDASK } \\
\text { TR } \\
\text { BR } \\
\text { MX }\end{array}$ & $\begin{array}{l}-2.2996 \\
-1.1934 \\
-1.5943 \\
-2^{* *} \\
-0.0839 \\
-0.2084\end{array}$ & $\begin{array}{r}0.3727 \\
0.4787 \\
-1.5839 \\
-4^{*} \\
0.0614 \\
0.3366\end{array}$ & $\begin{array}{r}0.1840 \\
0.3935 \\
-1.0158 \\
-3^{*} \\
-0.1891 \\
-0.6577\end{array}$ & $\begin{array}{l}-0.4813 \\
-0.7686 \\
0.2336 \\
0.5534 \\
-0.2487 \\
-0.7663\end{array}$ & $\begin{array}{r}14.8945 \\
1.3945 \\
-1.2523 \\
-0.3108 \\
1.4079 \\
0.5203\end{array}$ & $\begin{array}{r}-5.9079 \\
-1.3703 \\
-2.5070 \\
-0.7051 \\
-1.6294 \\
-2^{*}\end{array}$ & $\begin{array}{c}-1.9596 \\
-0.7520 \\
-3.9092 \\
-0.7702 \\
0.5736 \\
0.4725\end{array}$ & $\begin{array}{r}-5.8702 \\
-1.3339 \\
-2.17774 \\
-0.4464 \\
3.1718 \\
2^{*}\end{array}$ & $\begin{array}{r}2.1362 \\
0.1290 \\
-3.3839 \\
-0.7089 \\
0.4628 \\
0.3302\end{array}$ & $\begin{array}{r}3.9959 \\
2^{*} \\
-0.7974 \\
-0.7209 \\
0.7097 \\
0.4155\end{array}$ & $\begin{array}{c}-0.6452 \\
-0.5603 \\
-0.2160 \\
-0.3702 \\
0.1249 \\
0.2707\end{array}$ & $\begin{array}{r}-0.5119 \\
-8^{*} \\
1.3526 \\
0.5440 \\
-4.3279 \\
-2^{4}\end{array}$ \\
\hline R2 & $20 \%$ & $25 \%$ & $22 \%$ & $19 \%$ & $25 \%$ & $53 \%$ & $51 \%$ & $53 \%$ & $22 \%$ & $35 \%$ & $39 \%$ & $44 \%$ \\
\hline
\end{tabular}


Table 6: For each bond of country $j$ having weekly quotes for at least four maturity periods $m$, the dependent variable LtA $j m$ over the time period 9 August $2007-31$ March 2009 is estimated with the following

$\triangle A B S L t A_{j m t}=a_{j m t}+B_{1 m} \Delta(\text { DiB })_{t}+B_{2 m} \Delta(\text { FG-Liq })_{t}+B_{3 m} \Delta(\text { LN-Macro })_{t}+B_{4 m} \Delta(\text { USD Slope })_{t}+$ $B_{5 m} \Delta(\mathrm{VIX})_{t}+B_{6 m} \Delta(\mathrm{VIX}) * \Delta(\mathrm{VIX})_{t}+B_{7 m} \Delta(\text { Sentiment })_{t}+B_{8 m} \Delta(\mathrm{EM}-\mathrm{CDSI})_{t}+$

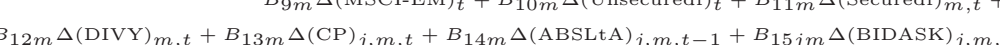
The panel includes the absolute LtA series (i.e. ABSLtA of three countries: Turkey, Brazil and Mexico), and the first ABSLtA lags. Variables are made stationary by taking first-differences. All independent variables
are the same as in Table 5. The sample is divided into two periods: liquidity crisis and credit crisis. Average parameter estimates are reported below, and the associated t-statistics for each parameter are displayed

\begin{tabular}{|c|c|c|c|c|c|c|c|c|}
\hline \multirow[t]{3}{*}{ Coefficients } & \multicolumn{4}{|c|}{ Liquidity Crisis Period } & \multicolumn{4}{|c|}{ Credit Crisis Period } \\
\hline & \multicolumn{4}{|c|}{ (9 August 2007 - 29 August 2008) } & \multicolumn{4}{|c|}{ (1 September 2008 - 31 March 2009) } \\
\hline & 1-3 Years & 3-6 Years & 6-9 Years & 9-15 Years & 1-3 Years & 3-6 Years & 6-9 Years & 9-15 Years \\
\hline DiB & $\begin{array}{l}-0.7675 \\
-1.4578\end{array}$ & $\begin{array}{l}-0.4381 \\
-0.8252\end{array}$ & $\begin{array}{l}-0.4747 \\
-0.8822\end{array}$ & $\begin{array}{l}-0.3116 \\
-0.6264\end{array}$ & $\begin{array}{r}7.1426 \\
2,5397^{*}\end{array}$ & $\begin{array}{l}0.2249 \\
0.1197\end{array}$ & $\begin{array}{r}4.2972 \\
2,1421^{*}\end{array}$ & $\begin{array}{r}4.2777 \\
1,9309 * *\end{array}$ \\
\hline FG-Liq & $\begin{array}{r}-0.4431 \\
-0.8422\end{array}$ & $\begin{array}{c}-0.1210 \\
-0.2322\end{array}$ & $\begin{array}{l}-0.1104 \\
-0.2026\end{array}$ & $\begin{array}{l}-0.3119 \\
-0.6412\end{array}$ & $\begin{array}{l}-0.8929 \\
-0.1444\end{array}$ & $\begin{array}{l}-15.3159 \\
-3,8946^{*}\end{array}$ & $\begin{array}{l}-22.2201 \\
-5,0531^{*}\end{array}$ & $\begin{array}{l}-26.4306 \\
-5,4655^{*}\end{array}$ \\
\hline LG-Macro & $\begin{array}{l}0.0127 \\
0.3397\end{array}$ & $\begin{array}{l}0.0264 \\
0.7195\end{array}$ & $\begin{array}{l}0.0053 \\
0.1392\end{array}$ & $\begin{array}{l}-0.0273 \\
-0.7687\end{array}$ & $\begin{array}{l}-0.2868 \\
-0.6634\end{array}$ & $\begin{array}{r}-0.8526 \\
-2,8778^{*}\end{array}$ & $\begin{array}{r}-1.7441 \\
-5,3303^{*}\end{array}$ & $\begin{array}{c}-2.4003 \\
-6,7042^{*}\end{array}$ \\
\hline USD Slope & $\begin{array}{l}-0.0484 \\
-0.4790\end{array}$ & $\begin{array}{l}0.0087 \\
0.0896\end{array}$ & $\begin{array}{l}0.0180 \\
0.1780\end{array}$ & $\begin{array}{l}0.0525 \\
0.5580\end{array}$ & $\begin{array}{l}0.3278 \\
0.7777\end{array}$ & $\begin{array}{l}0.0552 \\
0.1903\end{array}$ & $\begin{array}{l}0.7788 \\
2,306^{*}\end{array}$ & $\begin{array}{l}0.0624 \\
0.1731\end{array}$ \\
\hline VIX & $\begin{array}{l}-0.0020 \\
-0.3614\end{array}$ & $\begin{array}{l}-0.0030 \\
-0.5682\end{array}$ & $\begin{array}{l}-0.0009 \\
-0.1606\end{array}$ & $\begin{array}{l}-0.0031 \\
-0.6167\end{array}$ & $\begin{array}{l}0.0141 \\
0.4174\end{array}$ & $\begin{array}{r}-0.0505 \\
-2,1774^{*}\end{array}$ & $\begin{array}{c}-0.0550 \\
-2,1065^{*}\end{array}$ & $\begin{array}{r}-0.0693 \\
-2,4485^{*}\end{array}$ \\
\hline $\mathrm{VIX}^{2}$ & $\begin{array}{l}0.0013 \\
1.4192\end{array}$ & $\begin{array}{l}0.0010 \\
1.0663\end{array}$ & $\begin{array}{l}0.0010 \\
1.0401\end{array}$ & $\begin{array}{l}0.0001 \\
0.1194\end{array}$ & $\begin{array}{l}-0.0002 \\
-0.2066\end{array}$ & $\begin{array}{l}0.0021 \\
3,6242^{*}\end{array}$ & $\begin{array}{r}0.0029 \\
4,6933^{*}\end{array}$ & $\begin{array}{r}0.0034 \\
4,8836^{*}\end{array}$ \\
\hline Sentiment & $\begin{array}{l}0.02399 \\
1.3920\end{array}$ & $\begin{array}{l}0.0218 \\
1.2979\end{array}$ & $\begin{array}{l}0.0218 \\
1.2499\end{array}$ & $\begin{array}{l}0.0138 \\
0.8463\end{array}$ & $\begin{array}{l}-0.0168 \\
-0.2078\end{array}$ & $\begin{array}{r}0.2574 \\
4,8675^{*}\end{array}$ & $\begin{array}{c}0.3272 \\
5,5714^{*}\end{array}$ & $\begin{array}{r}0.3338 \\
4,9047^{*}\end{array}$ \\
\hline EM-CDSI & $\begin{array}{l}0.0353 \\
1.4681\end{array}$ & $\begin{array}{l}0.0235 \\
0.9988\end{array}$ & $\begin{array}{l}0.0035 \\
0.1473\end{array}$ & $\begin{array}{l}-0.0034 \\
-0.1470\end{array}$ & $\begin{array}{l}-0.0173 \\
-0.2610\end{array}$ & $\begin{array}{r}0.1030 \\
2,1665^{*}\end{array}$ & $\begin{array}{l}0.0779 \\
1.5213\end{array}$ & $\begin{array}{l}0.0534 \\
0.9758\end{array}$ \\
\hline MSCI-EM & $\begin{array}{r}0.0000 \\
-1,7579 * * *\end{array}$ & $\begin{array}{l}0.0000 \\
0.2465\end{array}$ & $\begin{array}{l}0.0000 \\
0.8885\end{array}$ & $\begin{array}{l}0.0000 \\
1.1193\end{array}$ & $\begin{array}{l}0.0001 \\
0.7927\end{array}$ & $\begin{array}{c}-0.0003 \\
-3,63644^{*}\end{array}$ & $\begin{array}{c}-0.0003 \\
-3,36^{*}\end{array}$ & $\begin{array}{r}-0.0003 \\
-3,0839 *\end{array}$ \\
\hline Unsecured US & $\begin{array}{l}-0.2151 \\
-1.2552\end{array}$ & $\begin{array}{l}-0.0383 \\
-0.2543\end{array}$ & $\begin{array}{l}0.0315 \\
0.2042\end{array}$ & $\begin{array}{l}0.11166 \\
0.7925\end{array}$ & $\begin{array}{l}0.4113 \\
0.8202\end{array}$ & $\begin{array}{l}0.1167 \\
0.3578\end{array}$ & $\begin{array}{l}0.4398 \\
1.2091\end{array}$ & $\begin{array}{l}-0.4325 \\
-1.02955\end{array}$ \\
\hline Secured US & $\begin{array}{l}0.2958 \\
1.3383\end{array}$ & $\begin{array}{r}0.3758 \\
2,1932^{*}\end{array}$ & $\begin{array}{l}0.0344 \\
0.2101\end{array}$ & $\begin{array}{r}0.3426 \\
1,7772^{* *}\end{array}$ & $\begin{array}{r}-1.0245 \\
-2,2487^{*}\end{array}$ & $\begin{array}{r}1.2249 \\
3,2049^{*}\end{array}$ & $\begin{array}{r}1.0956 \\
3,8669^{*}\end{array}$ & $\begin{array}{r}1.9369 \\
5,3023^{*}\end{array}$ \\
\hline DIVY & $\begin{array}{l}0.2316 \\
0.5888\end{array}$ & $\begin{array}{l}0.4452 \\
1.1677\end{array}$ & $\begin{array}{l}0.5042 \\
1.2862\end{array}$ & $\begin{array}{l}0.3273 \\
0.8644\end{array}$ & $\begin{array}{l}1.0369 \\
1.2251\end{array}$ & $\begin{array}{r}-1.1073 \\
-1,9154^{* *}\end{array}$ & $\begin{array}{l}-1.6527 \\
-2,7347^{*}\end{array}$ & $\begin{array}{r}-2.3962 \\
-3,6369^{*}\end{array}$ \\
\hline $\mathrm{CP}$ & $\begin{array}{r}-0.0011 \\
-2,3423^{*}\end{array}$ & $\begin{array}{l}-0.0007 \\
-1.6159\end{array}$ & $\begin{array}{r}-0.0005 \\
-0.9700\end{array}$ & $\begin{array}{l}-0.0001 \\
-0.2293\end{array}$ & $\begin{array}{l}-0.0068 \\
-1.3144\end{array}$ & $\begin{array}{l}0.0054 \\
1.4849\end{array}$ & $\begin{array}{r}0.0075 \\
1,949 * *\end{array}$ & $\begin{array}{r}0.0081 \\
1,9642^{*}\end{array}$ \\
\hline $\operatorname{ABSMLTA}(-1)$ & $\begin{array}{c}-0.4031 * \\
-5,2705^{*}\end{array}$ & $\begin{array}{r}-0.3806 \\
-4,8987^{*}\end{array}$ & $\begin{array}{l}-0.3821 \\
-4,7429 *\end{array}$ & $\begin{array}{r}-0.4192 \\
-5,4546^{*}\end{array}$ & $\begin{array}{r}-0.4379 \\
-4,1805^{*}\end{array}$ & $\begin{array}{c}-0.5651 \\
-6,8827^{*}\end{array}$ & $\begin{array}{c}-0.5814 \text {. } \\
-7,5774^{*}\end{array}$ & $\begin{array}{l}-0.4560 \\
-5,952^{*}\end{array}$ \\
\hline BIDASK & & & & & & & & \\
\hline TR & $\begin{array}{l}-3.0192 \\
-0.704\end{array}$ & $\begin{array}{l}-2.8523 \\
-1.438\end{array}$ & $\begin{array}{l}0.6453 \\
0.4799\end{array}$ & 0.5818 & $\begin{array}{c}51.2789 \\
1.3632\end{array} \mathrm{Cl} \mathrm{l}$ & $\begin{array}{l}-2.0514 \\
-0.1118\end{array}$ & $\begin{array}{l}1.7740 \\
0.3791\end{array}$ & 7.2872 \\
\hline BR & $\begin{array}{l}-0.7047 \\
-2.0750\end{array}$ & $\begin{array}{l}-1.43388 \\
-2.9633\end{array}$ & $\begin{array}{r}0.4799 \\
-2.3480\end{array}$ & $\begin{array}{r}0.2649 \\
-2.4605\end{array}$ & $\begin{array}{l}1.3632 \\
0.1184\end{array}-190$ & $\begin{array}{l}-0.1178 \\
0.7450\end{array}$ & $\begin{array}{r}0.3791 \\
-37.5471\end{array}$ & $\begin{array}{c}0.98499 \\
-0.0187\end{array}$ \\
\hline & -1.0615 & $-1,7441 * *$ & -1.2747 & $\begin{array}{r}-1.3230 \\
0601\end{array}$ & 0.0115 & 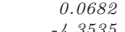 & -0.8788 & $\begin{array}{l}-0.0018 \\
50071\end{array}$ \\
\hline $\mathrm{MX}$ & $\begin{array}{l}1.9507 \\
1.5076\end{array}$ & $\begin{array}{l}-0.3236 \\
-0.8284\end{array}$ & $\begin{array}{l}-0.7564 \\
-1.2435\end{array}$ & $\begin{array}{l}0.6013 \\
0.9789\end{array}$ & $\begin{array}{r}-0.2191 \\
-0.0329\end{array}$ & $\begin{array}{r}-4.35355 \\
-1,9789^{*}\end{array}$ & $\begin{array}{r}-0.0453 \\
-0.0196\end{array}$ & $\begin{array}{r}5.0971 \\
1,7177^{* *}\end{array}$ \\
\hline R2 & $27 \%$ & $31 \%$ & $23 \%$ & $30 \%$ & $34 \%$ & $72 \%$ & $75 \%$ & $77 \%$ \\
\hline
\end{tabular}


Table 7: This table reports the measures of the price discovery process between the usd yield spreads and euro yield spreads of country $\mathrm{j}$ for the entire time period. The tests are based on the following VECM for each country:

$$
\begin{aligned}
& \Delta \$ C S_{t}=A 1\left(\$ C S_{t-1}-c_{1} E C S_{t-1}\right)+\sum_{n=1}^{N} \phi_{1 n} \Delta \$ C S_{t-n}+\sum_{n=1}^{N} \gamma_{1 n} \Delta E C S_{t-n}+u_{1 t} \\
& \Delta E C S_{t}=A 2\left(\$ C S_{t-1}-c_{1} E C S_{t-1}\right)+\sum_{n=1}^{N} \phi_{2 n} \Delta \$ C S_{t-n}+\sum_{n=1}^{N} \gamma_{2 n} \Delta E C S_{t-n}+u_{2 t}
\end{aligned}
$$

where $\$ C S$ and ECS are the usd and euro credit risk premiums, respectively, and $u_{1 t}$ and $u_{2 t}$ are the error terms. We imposed the restriction that $c_{1}=1$. The regressions are run using the optimal lags that are determined by AlC. Only the coefficients A1 and A2 are displayed in the table with t-statistics shown the table SM is the arithmetic mean of two Hasbrouck. The Hasbrouck measures for finding the contribution of usd credit risk premiums to euro credit risk the table SM is the ariums are estimated by the following expressions:

$$
S_{x}=\frac{A 2^{2}\left(\sigma_{1}^{2}-\frac{\sigma_{12}^{2}}{\sigma_{2}^{2}}\right)}{A 2^{2} \sigma_{1}^{2}-2(A 1 A 2) \sigma_{12}+A 1^{2} \sigma_{2}^{2}} \quad S_{y}=\frac{\left(A 2 \sigma_{1}-A 1 \frac{\sigma_{12}}{\sigma_{1}}\right)^{2}}{A 2^{2} \sigma_{1}^{2}-2(A 1 A 2) \sigma_{12}+A 1^{2} \sigma_{2}^{2}}
$$

\begin{tabular}{|c|c|c|c|c|c|}
\hline & A1 & A2 & $\mathbf{S}_{-} \mathbf{x}$ & $\mathbf{S} \_\mathbf{y}$ & SM \\
\hline 1-3 Years & $\begin{array}{c}-0.07 \\
{[-1.47325]}\end{array}$ & {$\left[\begin{array}{c}0.04 \\
{[0.60891]}\end{array}\right.$} & 0.03 & 0.80 & 0.42 \\
\hline 3-6 Years & $\begin{array}{c}-0.06 \\
{[-1.95186]}\end{array}$ & {$\left[\begin{array}{c}-0.01 \\
{[-0.18600]}\end{array}\right.$} & 0.01 & 0.68 & 0.35 \\
\hline 6-9 Years & $\begin{array}{c}-0.06 \\
{[-1.53779]}\end{array}$ & $\begin{array}{c}-0.01 \\
{[-0.24786]}\end{array}$ & 0.02 & 0.65 & 0.33 \\
\hline 9-15 Years & $\begin{array}{c}-0.08 \\
{[-1.44140]}\end{array}$ & $\begin{array}{c}-0.04 \\
{[-0.82162]}\end{array}$ & 0.23 & 0.29 & 0.26 \\
\hline \multicolumn{6}{|c|}{ Brazil } \\
\hline & A1 & A2 & $S_{-} \mathrm{x}$ & S_y & SM \\
\hline 1-3 Years & $\begin{array}{c}0.03 \\
{[0.87850]}\end{array}$ & $\begin{array}{c}0.17 \\
{[2.35342]}\end{array}$ & 0.84 & 0.88 & 0.86 \\
\hline 3-6 Years & {$\left[\begin{array}{c}0.02 \\
0.25500]\end{array}\right.$} & {$\left[\begin{array}{l}0.15 \\
1.74375]\end{array}\right.$} & 0.37 & 0.99 & 0.68 \\
\hline 6-9 Years & $\begin{array}{c}-0.03 \\
{[-0.32687]}\end{array}$ & {$\left[\begin{array}{c}0.14 \\
1.38201]\end{array}\right.$} & 0.19 & 0.99 & 0.59 \\
\hline 9-15 Years & $\begin{array}{c}-0.09 \\
{[-0.92882]}\end{array}$ & {$\left[\begin{array}{c}0.13 \\
1.33722]\end{array}\right.$} & 0.14 & 0.93 & 0.54 \\
\hline \multicolumn{6}{|c|}{ Mexico } \\
\hline & A1 & A2 & $\mathbf{S}_{-} \mathbf{x}$ & $\mathbf{S}_{-} \mathbf{y}$ & SM \\
\hline 1-3 Years & $\begin{array}{c}0.02 \\
{[0.41261]}\end{array}$ & {$\left[\begin{array}{c}0.36 \\
{[4.29644]}\end{array}\right.$} & 0.98 & 0.99 & 0.98 \\
\hline 3-6 Years & $\begin{array}{c}-0.16 \\
{[-1.55115]}\end{array}$ & {$\left[\begin{array}{c}0.11 \\
1.41120]\end{array}\right.$} & 0.13 & 0.84 & 0.49 \\
\hline 6-9 Years & $\begin{array}{c}-0.13 \\
{[-1.32086]}\end{array}$ & {$\left[\begin{array}{c}0.09 \\
{[1.44368]}\end{array}\right.$} & 0.14 & 0.89 & 0.51 \\
\hline 9-15 Years & $\begin{array}{c}-0.04 \\
{[-0.44613]}\end{array}$ & {$\left[\begin{array}{c}0.12 \\
2.27566]\end{array}\right.$} & 0.31 & 0.99 & 0.65 \\
\hline
\end{tabular}

Turkey 


\section{BRAZIL}
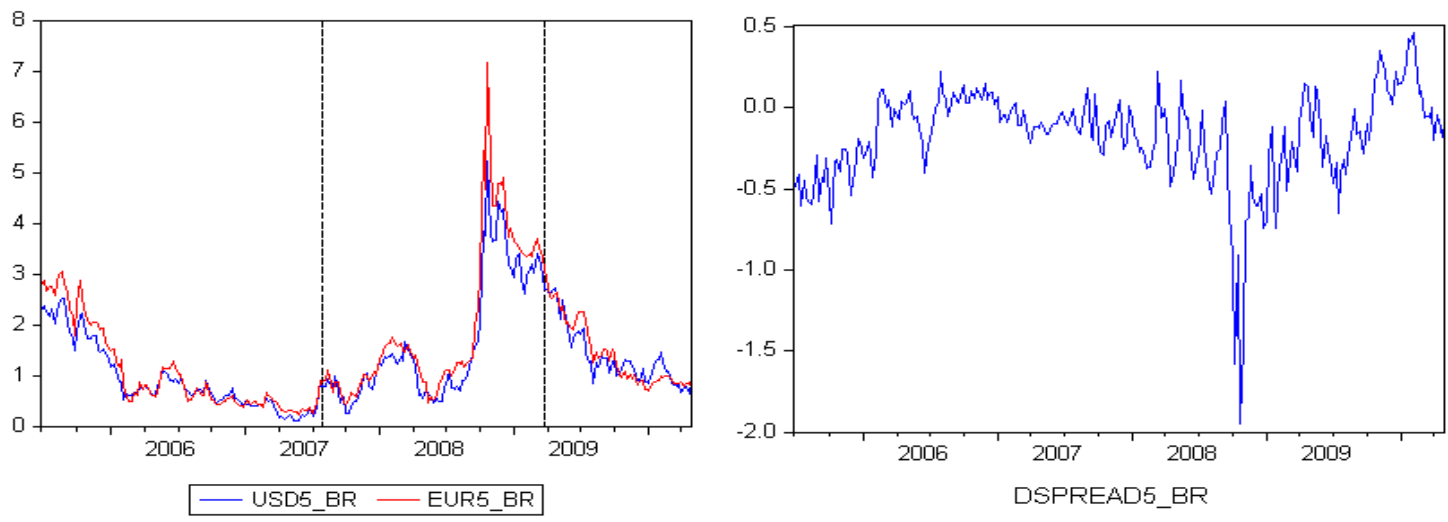

\section{MEXICO}
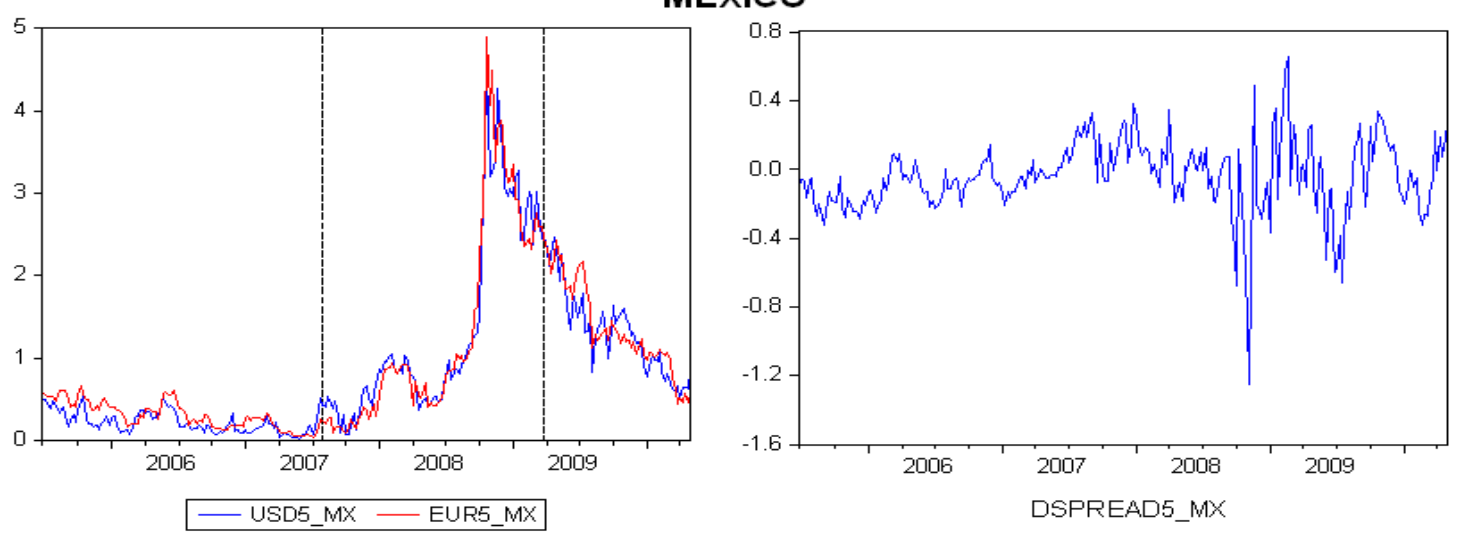

\section{TURKEY}
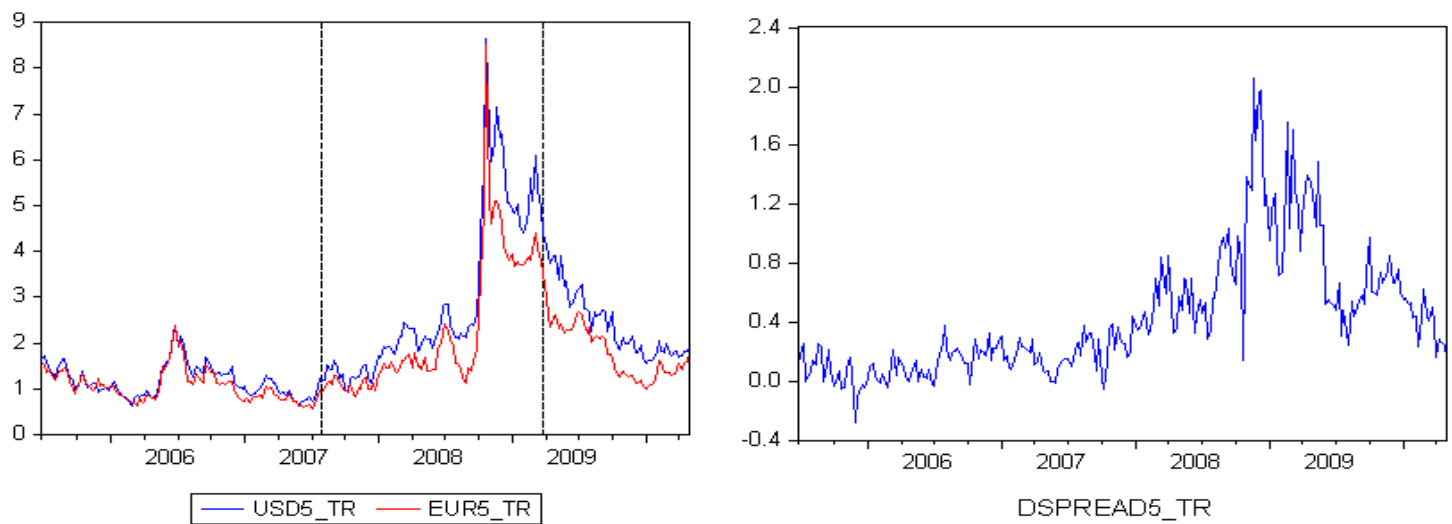

* The left column with USD5 and EUR5 displays the time-series of 5-year usd and eur risk premiums, respectively during each subsample across given countries. The right column with DSPREAD displays the time-series of 5-year currency dependence across given countries. BR stands for Brazil, MX for Mexico and TR for Turkey. The values are in percentages. 

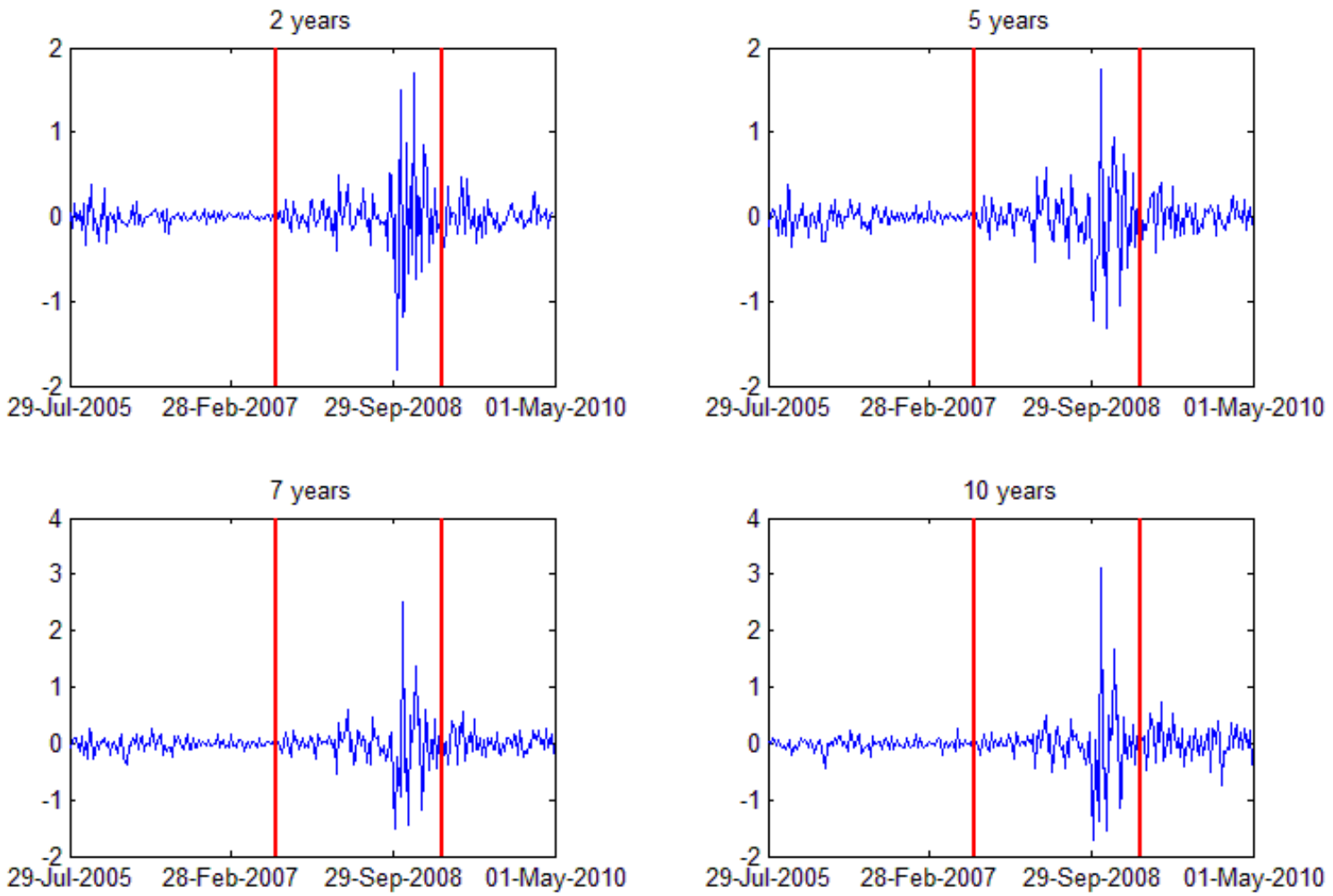

* Each graph represents the LtA proxy of the specific maturity bucket of Brazil. In terms of maturity buckets, 1-3 years is denoted by 2 years, 3-6 years is denoted by 5 years, 6-9 years is denoted by 7 years and 9-15 years is denoted by 10 years. The graphs are divided into three subsamples: pre-crisis, crisis and after-crisis, accordingly. The values are in percentages. 
Figure 2B
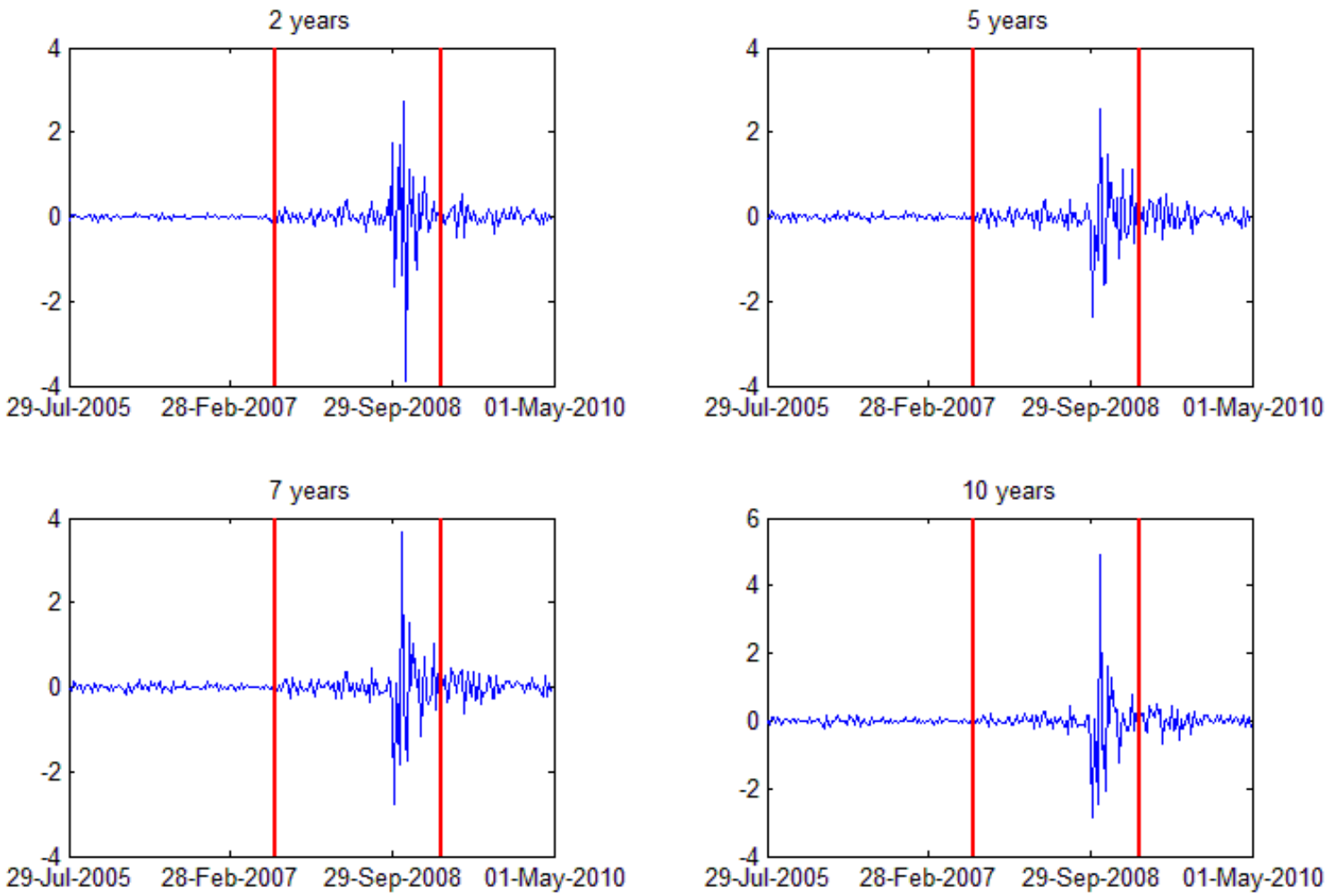

* Each graph represents the LtA proxy of the specific maturity bucket of Mexico. In terms of maturity buckets, 1-3 years is denoted by 2 years, 3-6 years is denoted by 5 years, 6-9 years is denoted by 7 years and 9-15 years is denoted by 10 years. The graphs are divided into three subsamples: pre-crisis, crisis and after-crisis, accordingly. The values are in percentages. 

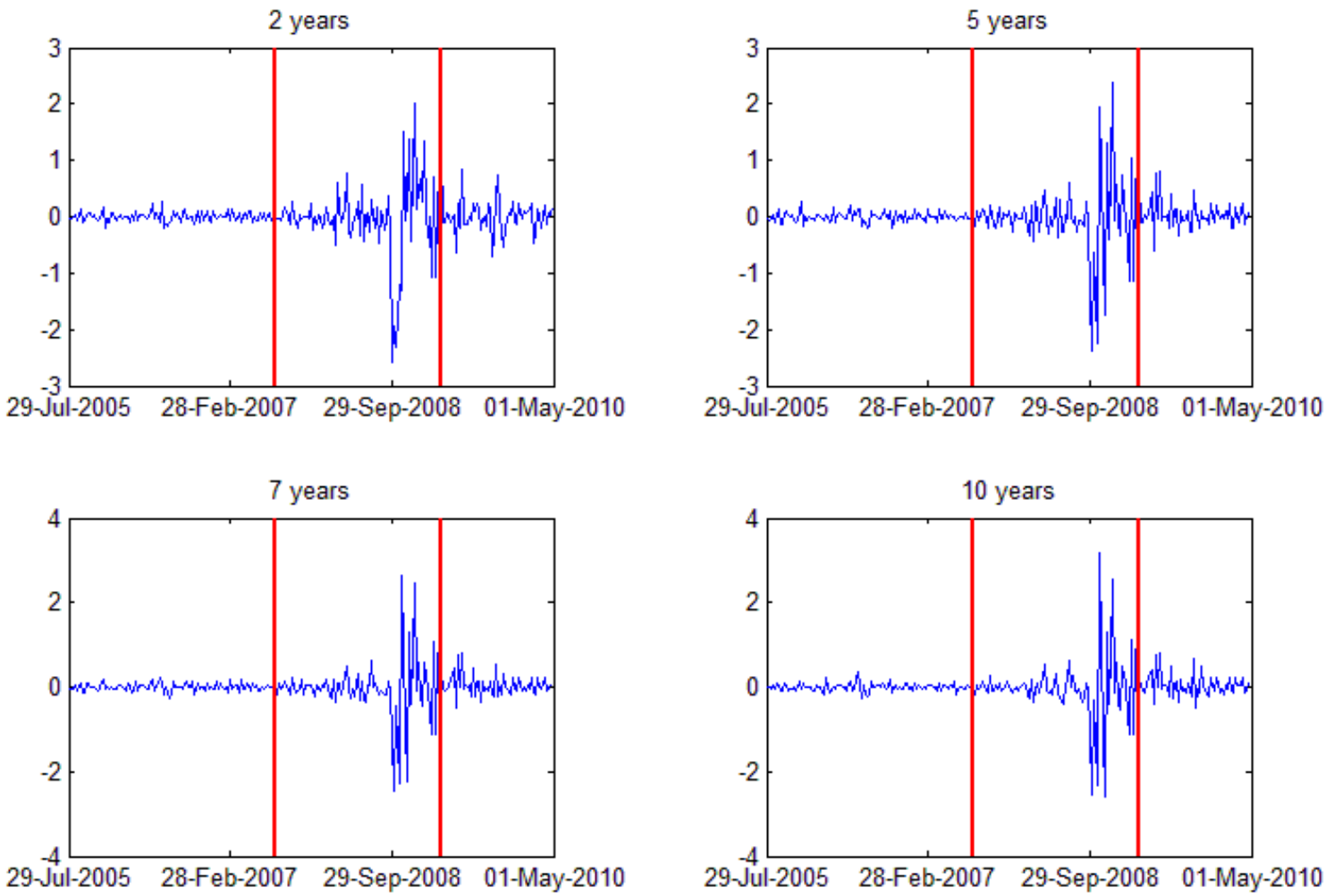

* Each graph represents the LtA proxy of the specific maturity bucket of Turkey. In terms of maturity buckets, 1-3 years is denoted by 2 years, 3-6 years is denoted by 5 years, 6-9 years is denoted by 7 years and 9-15 years is denoted by 10 years. The graphs are divided into three subsamples: pre-crisis, crisis and after-crisis, accordingly. The values are in percentages. 

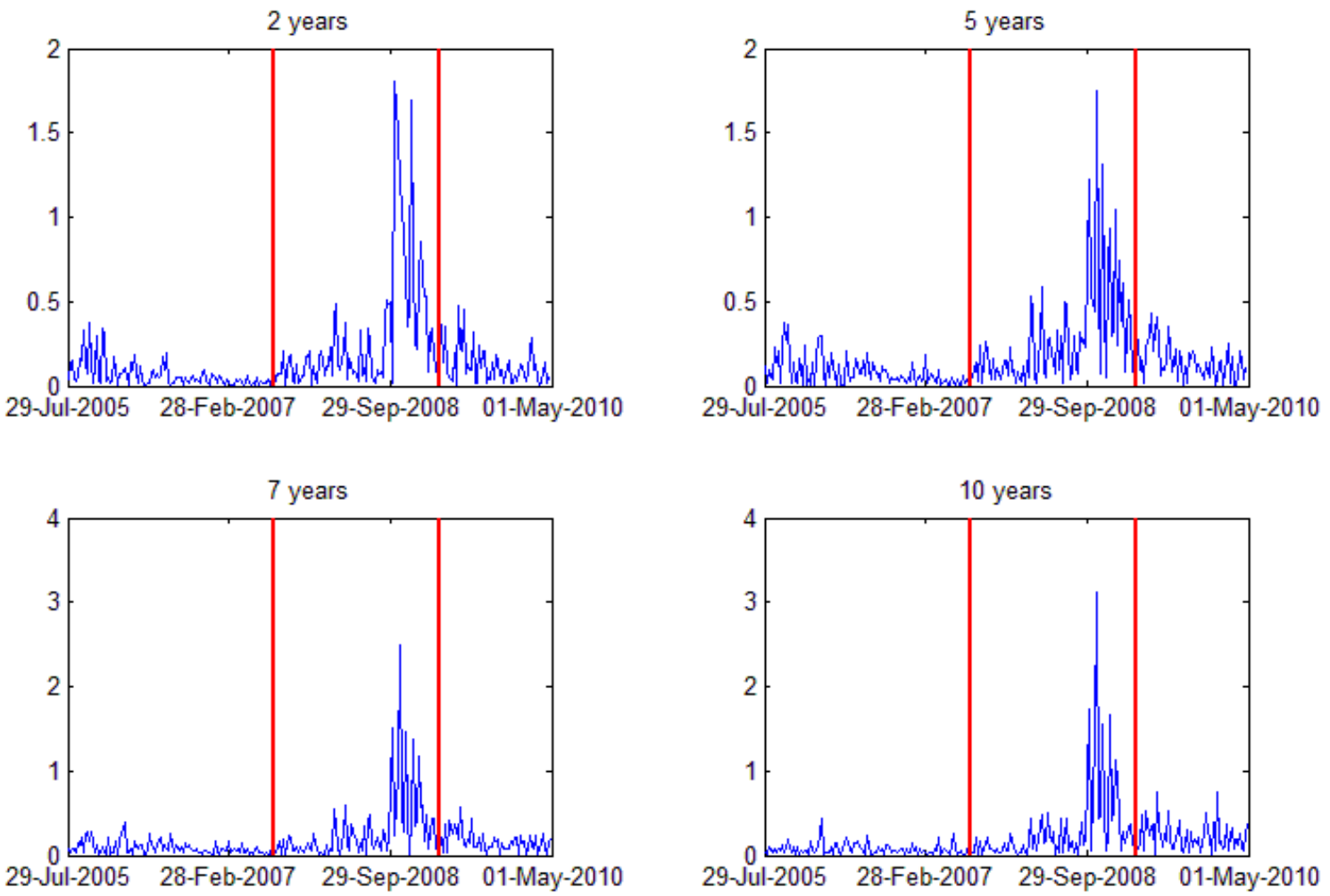

* Each graph represents the maturity-specific differential between the absolute LtA and the bid-ask spreads of usd-denominated bonds of Brazil. The graphs are divided into three subsamples: pre-crisis, crisis and after-crisis, accordingly. The values are in percentages. 
Comparative Analysis of ABS (LtA) and Bid-Ask Spreads in Mexico

Figure 3B
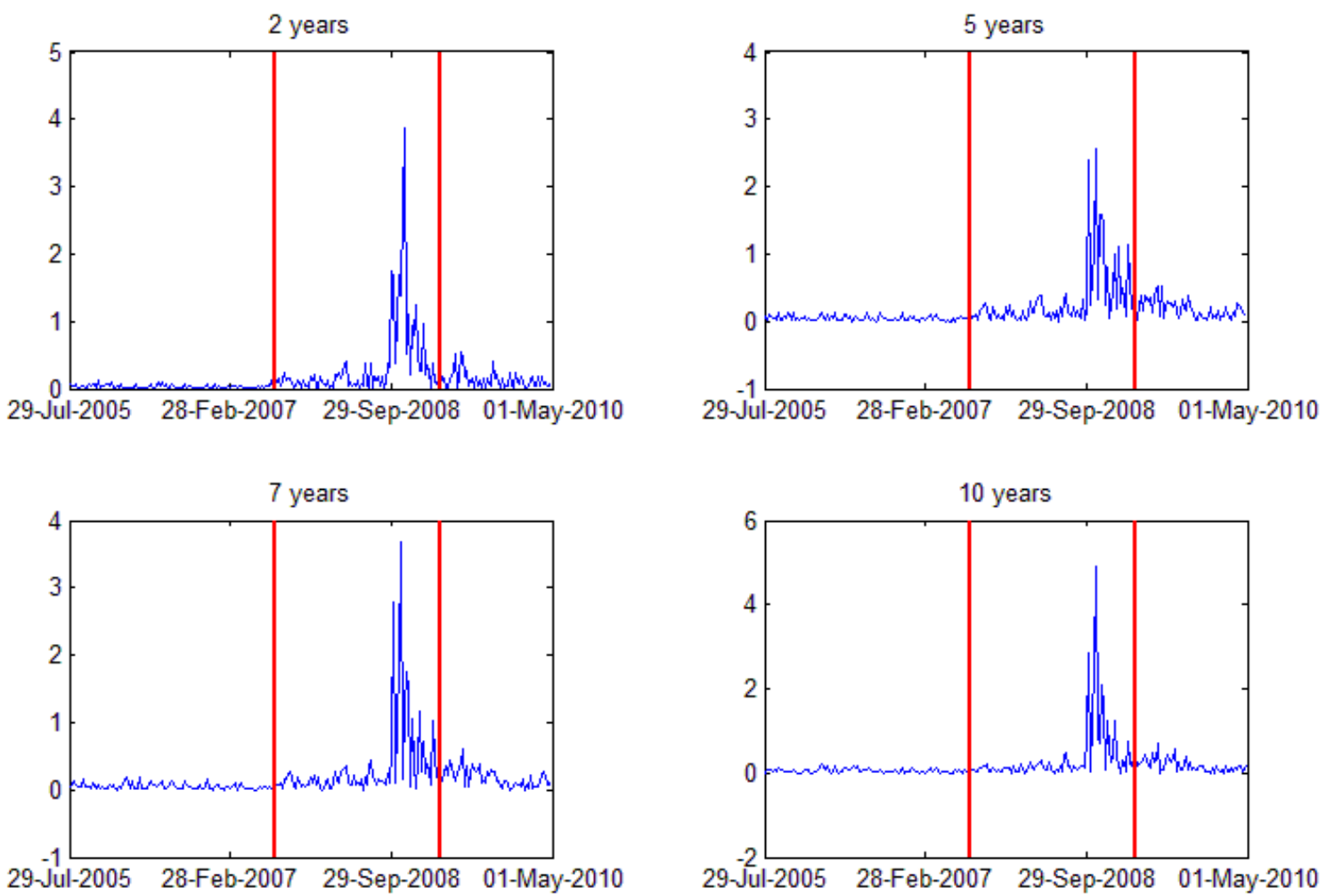

* Each graph represents the maturity-specific differential between the absolute LtA and the bid-ask spreads of usd-denominated bonds of Mexico. The graphs are divided into three subsamples: pre-crisis, crisis and after-crisis, accordingly. The values are in percentages. 
Comparative Analysis of ABS (LtA) and Bid-Ask Spreads in Turkey

Figure 3C
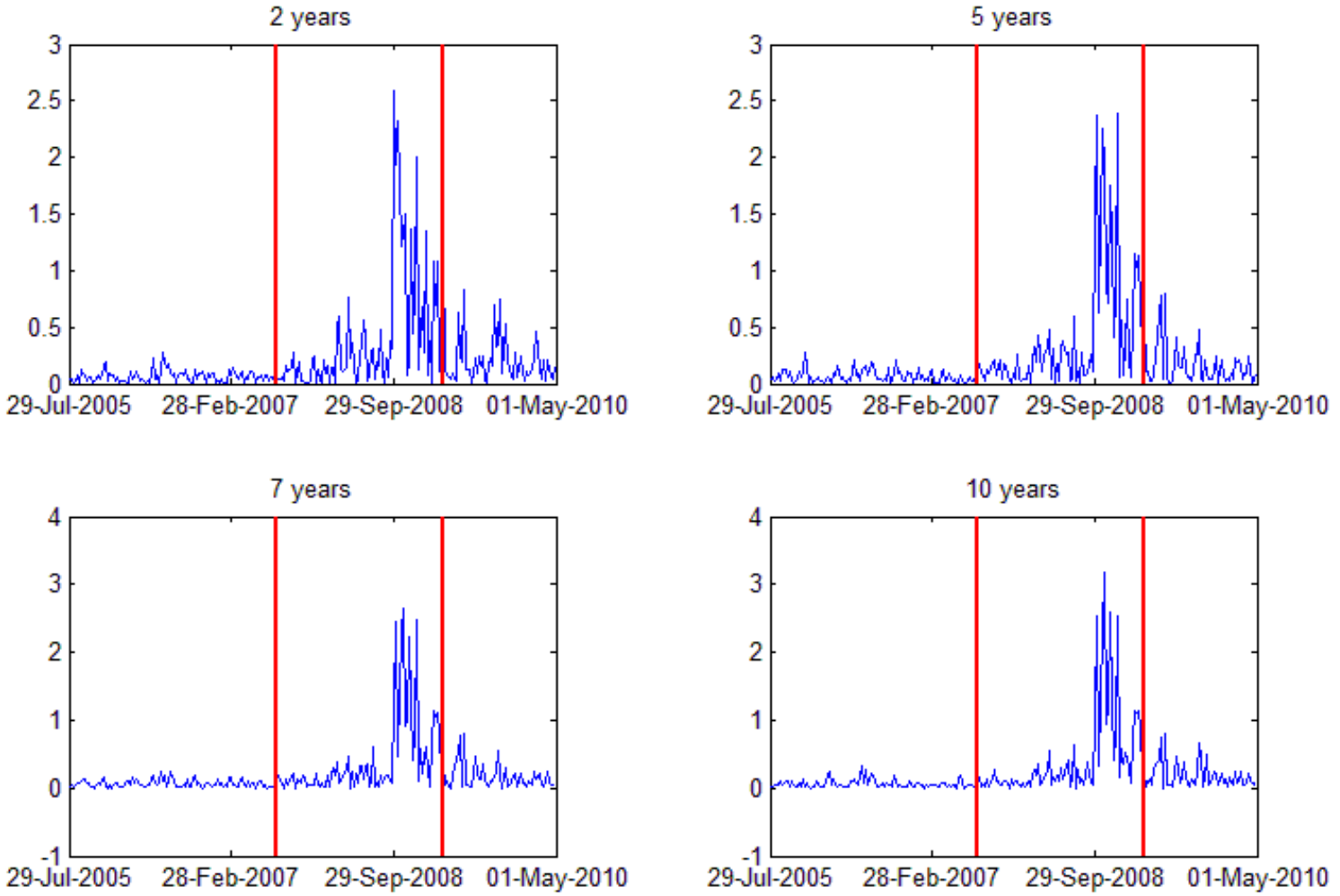

* Each graph represents the maturity-specific differential between the absolute LtA and the bid-ask spreads of usd-denominated bonds of Turkey. The graphs are divided into three subsamples: pre-crisis, crisis and after-crisis, accordingly. The values are in percentages. 
Unsecured Funding Costs and ABS LtA

Figure 4

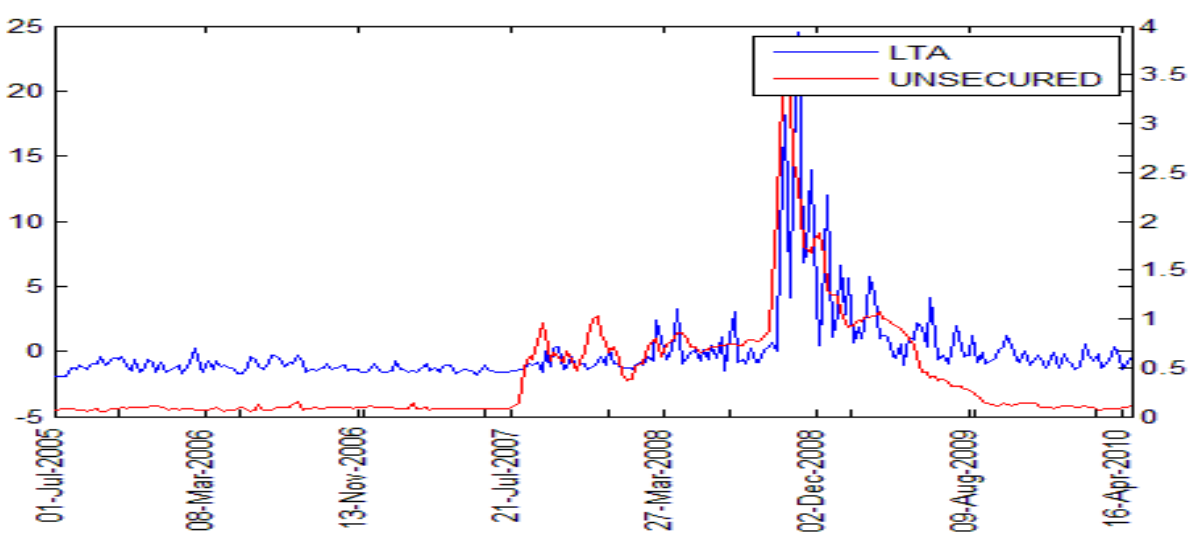

Secured Fundings Costs and ABS LtA Figure 5

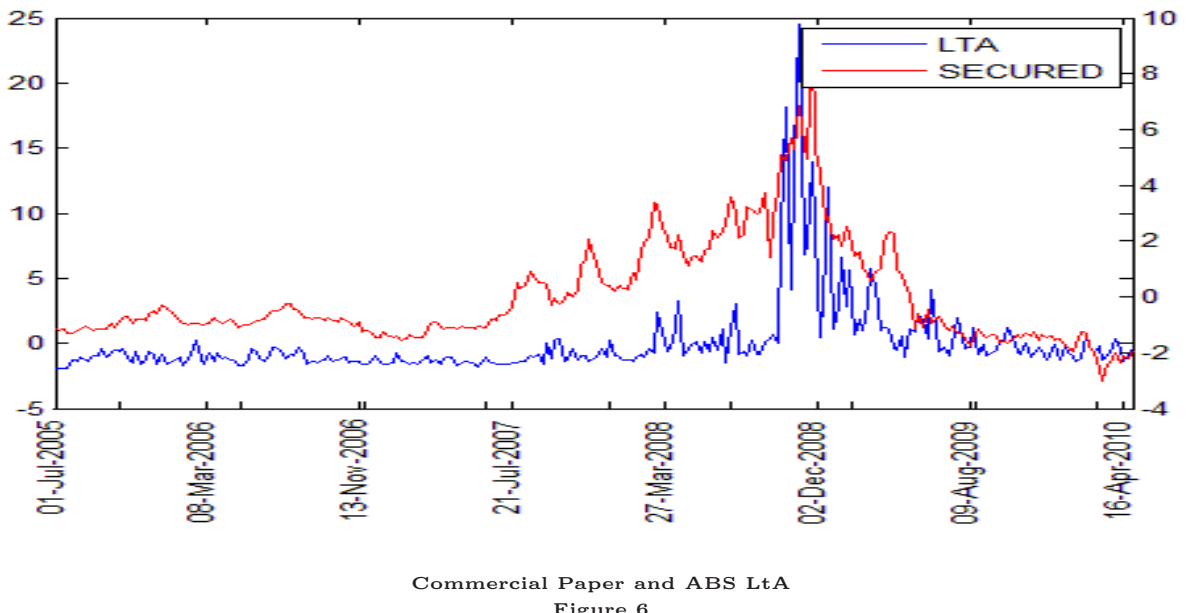

Figure 6

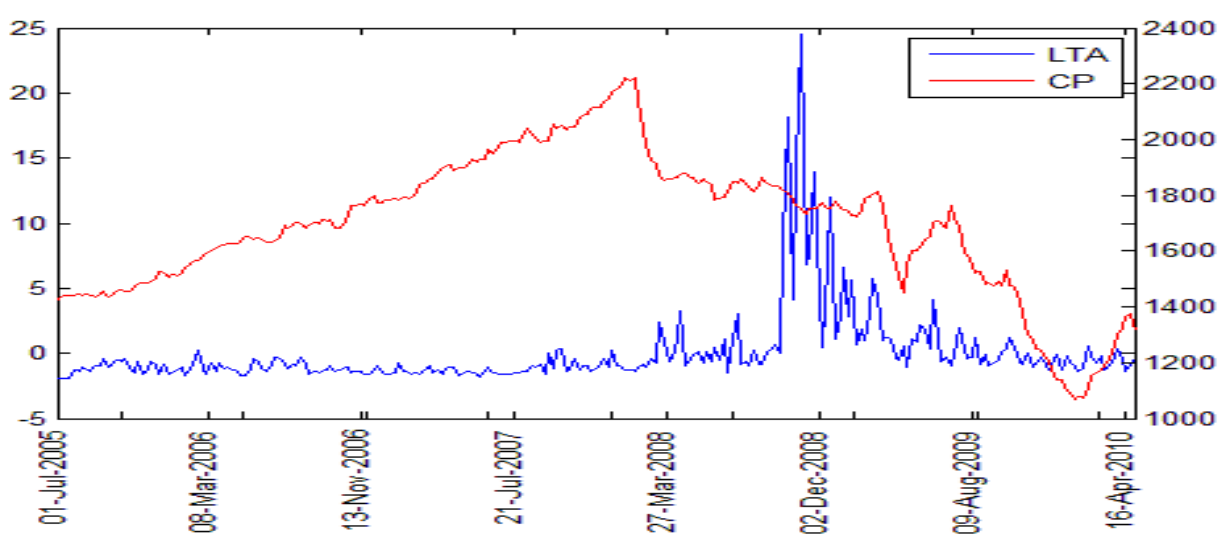


Sentiment and ABS LtA

Figure 7

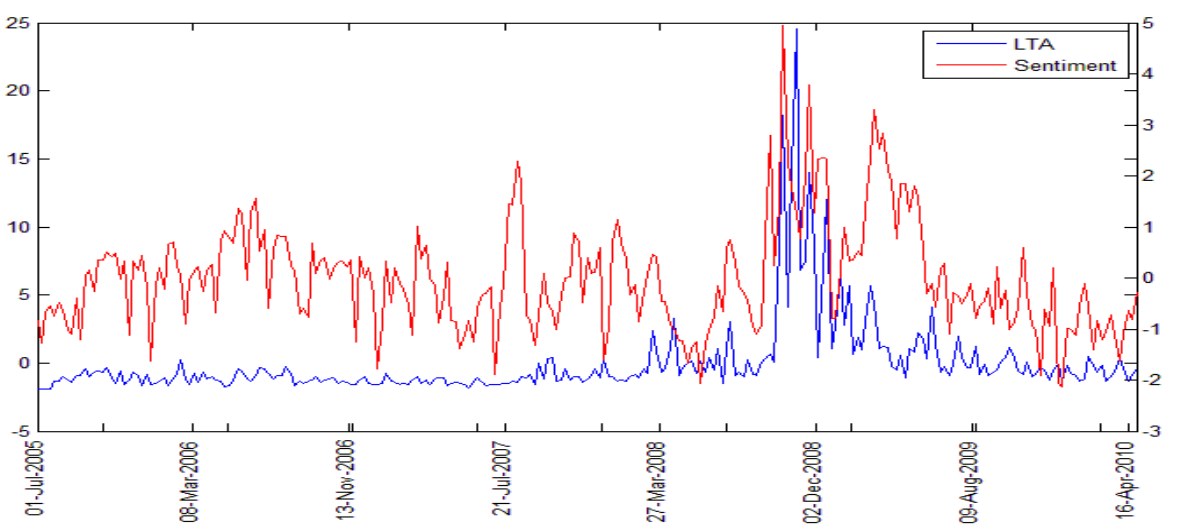

VIX and ABS LtA

Figure 8

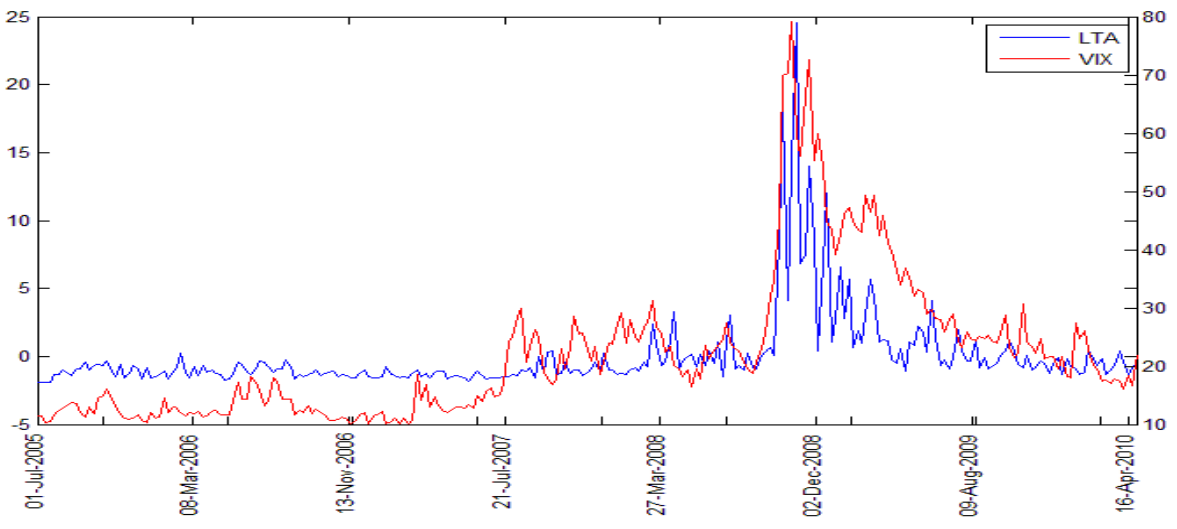


Marginal Contribution of Regressors

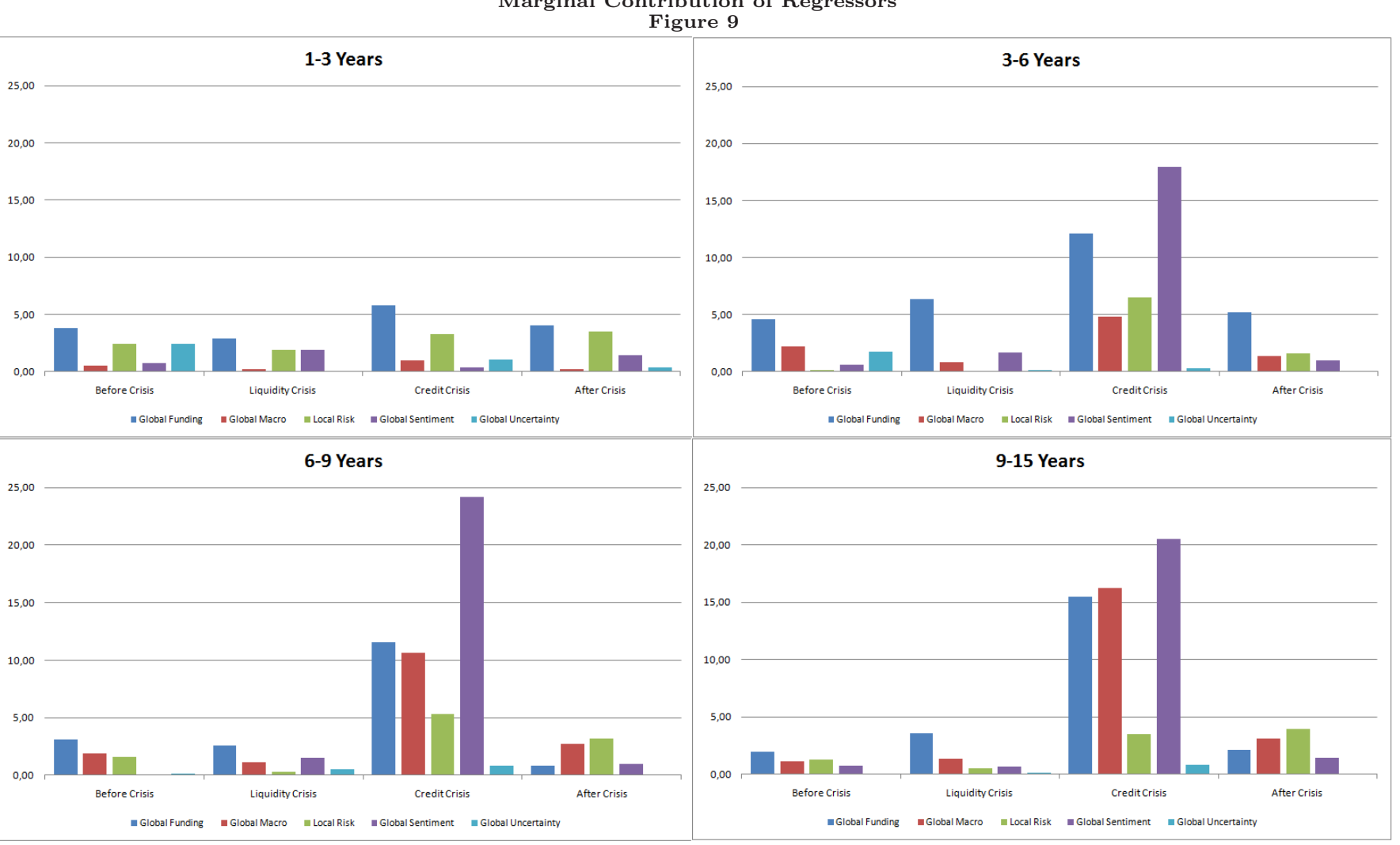

* The graphs display the marginal contribution of each market risk factor to the total $R^{2}$. The values are in percentages. In order to obtain the contributions of each market risk factor, original panels are regressed by excluding the corresponding risk factors from panels. If $P A N^{(1)}$ denotes the total $R^{2}$ of the panel with all regressors, and $P A N_{f}^{(2)}$ denotes the total $R^{2}$ of the the panels excluding the risk factor $f$, the

$$
M C_{f}=P A N^{(1)}-P A N_{f}^{(2)}
$$

